\title{
Contribuição ao conhecimento morfológico das espécies de leguminosae comercializadas no estado do Pará, como "angelim"1.
}

\author{
Gracialda Costa FERREIRA ${ }^{2}$ Michael John Gilbert HOPKINS ${ }^{3}$ Ricardo de S. SECCO ${ }^{4}$
}

\begin{abstract}
RESUMO
Sete espécies de Leguminosae comercializadas como "angelim", no estado do Pará, foram analisadas quanto aos aspectos morfológicos dos órgãos vegetativos e reprodutivos. Este estudo visou determinar diferenças básicas entre as espécies comercializadas com esta denominação vernacular, a fim de auxiliar no processo de identificação taxonômica das mesmas. Foi elaborada uma chave dicotômica para separar as espécies estudadas (Andira surinamensis, Dinizia excelsa, Hymenolobium excelsum, H. modestum, H. pulcherrimum, H. petraeum e Vatairea paraensis). As principais características utilizadas no campo, para separação das espécies estudadas, foram folha, folíolo, casca e tronco, porém, espécies de Andira, Hymenolobium e Vatairea, por apresentarem-se desprovidas de folhas no período fértil, necessitam de dados dos órgãos reprodutivos.
\end{abstract}

PALAVRAS-CHAVE

Andira, Dinizia, Hymenolobium, Vatairea, madeira, identificação.

\section{Contribution to the morphologic knowledge of the species of leguminosae in the state of Pará, traded as "angelim".}

\begin{abstract}
The morphology of vegetative and reproductive structures of seven species of Leguminosae traded as "angelim" in the State of Pará were analyzed. This study sought to determine the basic differences between the species traded under the same vernacular name, in order to facilitate their taxonomic identification. A dichotomous key was developed to distinguish the species studied (Andira surinamensis, Dinizia excelsa, Hymenolobium excelsum, H. modestum, H. pulcherrimum, H. petraeum and Vatairea paraensis). The main characteristics used for separation in the field were of leaf, leaflet, bark and trunk. However, flower or fruit characters are needed to identify those species of Andira, Hymenolobium and Vatairea that lose their leaves while flowering.
\end{abstract}

\section{KEY WORDS}

Andira, Dinizia, Hymenolobium, Vatairea, timber, identification.

\section{INTRODUÇÃO}

Leguminosae Adans. (Fabaceae) é uma família vasta, cosmopolita e geologicamente antiga (Muniz 1986). Está ausente apenas nas regióes ártica e antártica, sendo pobremente representada na Nova Zelândia. Os trópicos são particularmente ricos em espécies herbáceas e lenhosas dessa família (Bukart 1952). É de grande importância para a flora amazônica, cabendo-lhe o primeiro lugar entre os vegetais lenhosos, quanto ao número de gêneros e espécies, sendo ainda "uma das famílias mais naturais do sistema botânico" (Ducke 1949). É a terceira maior família entre as plantas com flores (fanerógamas) de acordo com Lima et al. (1994). Sua importância econômica é muito diversificada, sendo utilizada desde a alimentação humana e animal até na produção de corantes, óleos, perfumes, inseticidas, e ainda apresenta uso medicinal, agronômico (enriquecimento de solos), ornamental e, principalmente, para produção de madeiras nobres e valiosas usadas na marcenaria, entalhadura e construções em geral. Lima et

\footnotetext{
${ }^{1}$ Parte integrante da dissertação de Mestrado do primeiro autor. Programa de Mestrado em Ciências Florestais, Universidade Federal Rural da Amazônia. Desenvolvido através do projeto Dendrogene (Embrapa Amazônia Oriental/DFID)

${ }^{2}$ CAPES/UFRA, Tv. Barão do Triunfo 2885 - C-56, Belém-PA, 66093-390, Tel. 246-5579 e-mail: gracialdaf@yahoo.com.br

${ }^{3}$ SAPECA, Enéas Pinheiro s/n - Cx.P. 48, Belém-PA, 66093-100, Tel. 299-4539 e-mail:pfrd@argo.com.br

${ }^{4}$ Museu Goeldi, pesquisador. E-mail: secco@museu-goeldi.br
} 


\section{ACTA \\ AMAZONICA}

CONTRIBUICCÃO AO CONHECIMENTO MORFOLÓGICO DAS ESPÉCIES

DE LEGUMINOSAE COMERCIALIZADAS NO ESTADO DO PARÁ, COMO "ANGELIM" al. (1994) relataram que as leguminosas vêm sendo apontadas como uma das principais fontes para a produção de proteína vegetal, particularmente para os países subdesenvolvidos.

A família Senso Judd et al. (1999), está dividida em três subfamílias (Caesalpinioideae, Mimosoideae e Papilionoideae) com aproximadamente 18.000 espécies, distribuídas em 619 gêneros, pertencendo boa parte originalmente à flora brasileira (Polhill \& Raven 1981; Joly 1993). Suas espécies apresentam hábito muito variado, desde grandes árvores, arbustos, ervas e trepadeiras, tanto escandentes como volúveis, encontradas em diferentes ambientes. Quase sempre apresentam folhas compostas; filotaxia alterna e sempre com estípulas na base; flores actinomorfas ou zigomorfas, com cálice mais freqüentemente gamossépalo, podendo apresentar-se dialissépalo e corola dialipétala, (nas Mimosoideae aparece a gamopetalia), androceu geralmente com 10 estames, podendo apresentar menor ou maior número, livres ou soldados; ovário com inserção acima das peças florais, com um ou muitos óvulos; o fruto em geral é um legume, porém, podem apresentar outros tipos como lomento, folículo e sâmara (Barroso et al. 1991).

A identificação das espécies durante os inventários florestais é realizada com base em nomes vernaculares, com auxílio de mateiros, os quais relacionam nomes às árvores e, posteriormente, no escritório são relacionados os nomes científicos de acordo com a literatura acessível a cada região ou empresa. Esse procedimento pode gerar prejuízos ecológicos irreparáveis para a conservação das espécies, já que nesse momento, estará sendo realizada a seleção das árvores que serão exploradas, porta-sementes e remanescentes sem considerar as características morfológicas, fisiológicas ou mesmo tecnológicas de cada espécie e assim não garantindo a continuidade da espécie para aquele ambiente ou área.

Estudos morfológicos envolvendo caracteres vegetativos de espécies comerciais requerem tempo, visto que é muito difícil coletar material botânico fértil, primeiramente, pela dificuldade de acesso às árvores (distância $\mathrm{x}$ recursos), e, também pelas espécies apresentarem diferentes épocas de floração que muitas vezes não coincidem com as excursões botânicas, ou ainda, quando estão em período fértil, produzem flores diminutas a muitos metros do solo, passando desapercebidas pelos coletores.

No Estado do Pará, é comum a comercialização da madeira denominada "angelim", principalmente na confecção de móveis e construção de casas, apresentando importância econômica considerável no comércio paraense pelo uso que apresenta, principalmente para pequenos e médios empresários.

Através de levantamento bibliográfico em literaturas específicas e em acervos dos principais herbários da Amazônia (Ferreira et al. no prelo), foram identificadas 21 espécies de Leguminosae conhecidas, no Estado do Pará, como "angelim", as quais estão distribuídas em 11 gêneros (Andira Juss., Bowdichia Kunth, Dimorphandra Schott, Dinizia Ducke,
Enterolobium Mart., Hymenaea L., Hymenolobium Benth., Parkia R.Brown, Vatairea Aubl., Vataireopsis Ducke e Zygia P.Browne). Por se tratar de espécies e até mesmo gêneros diferentes, esse tipo de denominação popular, além de gerar erros graves, leva a prejuízos financeiros na hora da comercialização da madeira proveniente de diferentes espécies, porque o uso do nome vernacular não associa características às espécies comercializadas, levando a uma heterogeneidade no produto final.

Deste conjunto de espécies, até o momento foram reconhecidas sete sendo comercializadas com a denominação de "angelim", são elas: Andira surinamensis (Bondt) Splitg. ex Amshoff, Dinizia excelsa Ducke, Hymenolobium excelsum Ducke, $H$. petraeum Ducke, $H$. pulcherrimum Ducke, H. modestum Ducke e Vatairea paraensis Ducke (Ferreira et al. no prelo).

Visando determinar diferenças básicas entre as espécies de angelim comercializadas na região, e facilitar o conhecimento biológico dessas espécies, foi realizado o estudo de suas características morfológicas. Pretende-se com o presente estudo, minimizar o problema causado pela utilização apenas da nomenclatura vernacular, durante a comercialização das madeiras de angelim.

\section{MATERIAL E MÉTODOS}

As espécies foram selecionadas com base no levantamento bibliográfico e em acervos dos herbários HAMAB (Herbário do Instituto de Pesquisas Científicas e Tecnológicas do Estado do Amapá), IAN (Embrapa Amazônia Oriental), INPA (Instituto Nacional de Pesquisas da Amazônia), MG (Museu Paraense Emílio Goeldi) e RB (Instituto Jardim Botânico do Rio de Janeiro). Todo o material utilizado foi proveniente de coletas realizadas na área física da Embrapa Amazônia Oriental (Belém-PA), na Área de Pesquisas Ecológicas do Guamá - APEG (Belém-PA), no Bosque Municipal Rodrigues Alves (Belém-PA), no Campo Experimental da Embrapa (Moju-PA), nas áreas de exploração das madeireiras Juruá Florestal Ltda. (Moju-PA) e Cikel Brasil Verde S.A. (Paragominas-PA), Fundação Floresta Tropical (Paragominas/Ulianópolis-PA), Floresta Nacional de Caxiuanã (Melgaço-PA), rios Anapu e Pacajá (Portel-PA), Abaetetuba-PA e Flona do Tapajós (SantarémPA). Dos indivíduos que não foi possível coletar material fértil, utilizaram-se dados de exsicatas dos herbários IAN, INPA, MG e RB. Das amostras analisadas, são citadas no texto apenas as usadas para desenhos e mensurações.

Depois de identificadas as espécies conhecidas como angelim, procederam-se as coletas nas serrarias dos principais pólos madeireiros, para verificar quais espécies estavam sendo comercializadas no Estado do Pará.

A coleta e preparação de material botânico seguiram técnicas padronizadas (Instituto de Botânica 1984). Para a identificação taxonômica, utilizou-se chaves dicotômicas de identificação, literatura especializada e comparação com material de herbário; posteriormente foram preparadas 


\section{ACTA AMAZONICA}

CONTRIBUIÇÃO AO CONHECIMENTO MORFOLÓGICO DAS ESPÉCIES DE LEGUMINOSAE COMERCIALIZADAS NO ESTADO DO PARÁ, COMO "ANGELIM" exsicatas e registradas no Herbário IAN. Das exsicatas, retiraram-se informações de habitat, nome vernacular, hábito, distribuição geográfica e características de cor da flor e fruto e presença de exsudato.

A descrição morfológica foi baseada nas observações de campo e de laboratório, com auxílio do estereomicroscópio Zeiss. Foram mensurados folhas, folíolos e pecíolos do material desidratado, medindo-se pelo menos cinco folhas de cada indivíduo. Os desenhos foram realizados em câmara clara, acoplada a um estereomicroscópio, utilizando-se material desidratado e em meio líquido, sendo que partes florais das exsicatas foram hidratadas, fervendo-se em água por aproximadamente $3 \mathrm{~min}$. Diferentes aumentos foram utilizados para visualizar detalhes da espécie e desenhar as estruturas que ajudam a identificá-las. As amostras botânicas foram estudadas sob o ponto de vista morfológico, englobando aspectos de campo, como: hábito, caule, folha, inflorescência, frutos e sementes.

A terminologia utilizada na descrição da forma das folhas e das peças florais seguiu as propostas de Stearn (1983) e Ribeiro et al. (1999), ritidoma e casca segundo Ribeiro et al. (1999), inflorescências e frutos foi de acordo com Barroso et al. (1997; 1999); a referência da diagnose das espécies foi obtida da consulta aos "sites" (http://www.mobot.org, http:// www.ildis.org) e literatura específica; os nomes vernaculares e as áreas de ocorrência foram baseadas nos acervos dos herbários HAMAB, IAN, INPA, RB e MG e em literatura específica. A classificação das espécies estudadas está de acordo com Polhill \& Raven (1981). Para cada espécie estudada, foram relacionados nomes genéricos, epíteto específico, respectiva autoria, referência da diagnose, citação dos tipos, descrição, áreas de ocorrência na Amazônia brasileira, fenologia, nomes vernaculares, material examinado e ilustrações com fotografias e desenhos. O nome vernacular mais utilizado nas áreas de coleta encontra-se em negrito.

\section{RESULTADOS E DISCUSSÃO}

\section{Aspectos Morfológicos}

Hábito - Todas as espécies estudadas são árvores grandes a muito grandes. O maior representante é Dinizia excelsa, que chega a ultrapassar os $50 \mathrm{~m}$ de altura. Apenas Andira surinamensis apresenta indivíduos com porte pequeno emáreas abertas como campo, cerrados ou capoeiras ou ainda cultivada, entretanto, na floresta apresenta porte mediano a grande.

Caule - Na maioria das espécies o caule/fuste é ereto, com pouca tortuosidade, quase sempre circular a cônico, com 20-25m de altura e $5 \mathrm{~m}$ de altura em indivíduos de Andira surinamensis, encontrados em áreas abertas.

Base do tronco (raiz) - Quase todas as espécies apresentam sapopemas na base do tronco, muitas vezes chegando a 3-4m do solo em Dinizia excelsa e são, na maioria retas, côncavas e poucas vezes ramificadas. Andira surinamensis é desprovida de sapopemas.
Ritidoma - A parte mais externa da casca morta apresenta características muito importantes para a caracterização macromorfológica das espécies. Em quase todas as espécies há desprendimento em placas, que variam de grandes a pequenas, com diferentes formas. Em Dinizia excelsa o ritidoma é marrom-avermelhado com desprendimento em grandes placas vermelhas, que dão ao tronco um aspecto escamoso, sendo que são espessas, até $5 \mathrm{~cm}$ espessura, coriáceas, pétreas, formando grandes amontoados na base do tronco; já em Andira surinamensis é marrom-acinzentadoclaro, estriado a fissurado superficialmente, com desprendimento em pequenas placas cartáceas a subcoriáceas e retangulares; em Vatairea paraensis é marromavermelhado, com estrias rasas, reticulado, com depressões formando manchas claras, estrias superficiais paralelas em linhas verticais formadas por pequenas lenticelas, não apresentando desprendimento. Nas espécies de Hymenolobium não há grandes variações quanto à cor que é marrom-avermelhado, variando a marrom-acinzentado em H. excelsum e H. petraeum. O desprendimento em placas só não foi observado em $H$. pulcherrimum, e todas são pequenas, coriáceas deixando marcas avermelhadas quando caem. Em todas as quatro espécies de Hymenolobium ocorrem lenticelas grandes (até $1 \mathrm{~cm}$ ), espocadas, proeminentes e dispersas; estrias rasas ou pouco profundas foram observadas em $H$. modestum, $H$. petraeum e $H$. pulcherrimum, sendo que no primeiro podem ser horizontais e verticais, e com aspecto de reticulado no último.

Corte: Casca morta - Na maioria das espécies é marromavermelhada, clara, fina com espessura de $1-1,5 \mathrm{~mm}$, sendo que em Hymenolobium excelsum e $H$. petraeum são um pouco mais espessas (até $2,5 \mathrm{~mm}$ ). Em geral é dura a pétrea em algumas espécies de Hymenolobium, às vezes apresenta aspecto de cortiça, exceto em Andira surinamensis, que é mais porosa. Casca viva - Encontrada logo após o câmbio cortical, a casca viva em Dinizia excelsa é branco-amarelada, distinguindo-a das demais espécies, e bem espessa (até $2,5 \mathrm{~cm})$; em Andira surinamensis e Vatairea paraensis apresenta-se rosada, oxidando após alguns minutos a alaranjada, em função da resina incolor que exsuda, e é menos espessa que Dinizia excelsa, sendo de $4 \mathrm{~mm}$ de espessura em Andira surinamensis e até $5 \mathrm{~mm}$ de espessura em Vatairea paraensis. Nas espécies de Hymenolobium, a casca viva varia de marrom-avermelhada, em $H$. excelsum, a alaranjada em H. pulcherrimum, até róseo-amarelada, escura, ou rosada em $H$. modestum e $H$. petraeum, ficando sempre mais amarelo-clara próximo ao alburno. É relativamente espessa (até $2 \mathrm{~cm}$ ), fibrosa ou porosa em $H$. petraeum, as fibras mais escuras destacam-se, dando aspecto de veias. Exsudatos Todas as espécies estudadas exsudam resina, com odor característico de legume. Em Dinizia excelsa, Andira surinamensis e Vatairea paraensis é incolor, já nas espécies de Hymenolobium é vermelha, consistente e pegajosa.

Folhas - Todas as sete espécies apresentam folhas compostas, sendo que em Dinizia excelsa é bipinada e pinada nas demais. Essa característica separa Dinizia das 


\section{ACTA \\ AMAZONICA}

CONTRIBUICÃO AO CONHECIMENTO MORFOLÓGICO DAS ESPÉCIES

DE LEGUMINOSAE COMERCIALIZADAS NO ESTADO DO PARÁ, COMO "ANGELIM" outras espécies. Andira surinamensis e Vatairea paraensis apresentam as folhas com até nove folíolos. Entretanto, em Andira são maiores que em Vatairea. Em Hymenolobium, esta é uma característica que pode ser utilizada para separar as espécies, visto que em $H$. excelsum os folíolos são bem pequenos e numerosos, em $H$. modestum a folha apresentase pendente (nas demais eretas) e os folíolos são mais coriáceos; em $H$. petraeum, as folhas são maiores que em $H$. modestum e glabras enquanto, em $H$. pulcherrimum apresentam pubescência acentuada.

Inflorescência - O tipo de inflorescência predominante nas espécies de Andira, Hymenolobium e Vatairea é o heterocládio duplo racemo, sendo que as diferenças são encontradas no tamanho e pubescência, bem como no tamanho e forma das brácteas e bractéolas. Dinizia excelsa apresenta inflorescência do tipo espiciforme, diferenciandose, assim, das demais.

Frutos - Três tipos de frutos são encontrados nas espécies estudadas. Em Dinizia excelsa é do tipo legume samaróide; em Andira surinamensis é uma drupa; nas espécies de Hymenolobium e Vatairea o tipo é sâmara, sendo que em Vatairea paraensis há projeções alares desenvolvidas da parede ovariana. Em $H$. excelsum e $H$. petraeum observa-se a persistência do cálice e androceu na base do fruto, o que é comum na maioria das espécies do gênero.

\section{ASPECTOS TAXONÔMICOS}

\section{Posição sistemática e afinidades genéricas}

\section{Leguminosae-Mimosoideae, Mimoseae}

Dinizia Ducke, Arch. Jard. Bot. do Rio de Janeiro 3: 7677, t. 4.1922.

O gênero Dinizia é monotípico, ocupando posição intermediária entre Mimosoideae, através de Piptadenia e Stryphnodendron, gêneros com os quais se assemelha em todos os aspectos da árvore, e Caesalpinoideae, apresentando grande afinidade com Dimorphandra na prefloração perfeitamente imbricada do cálice, o que a faz muito próxima de Caesalpinoideae (Ducke 1949). Para Luckow et al. (2000), parece que a forma tetraedal do pólen é a única característica que a coloca em Mimosoideae.

O nome Dinizia foi dado como homenagem a um amigo de Ducke, o Dr. I.A.Picanço Diniz (Ducke 1922; Barroso et al. 1991).

Leguminosae-Papilionoideae, Dalbergieae

Andira Lam., Encyc. 1:171. 1783; H.B.K., Nov. Gen. et Spec. Amer. 6:385 (1823); DC, Prodr. 2:475 (1825); Bentr. in Ann. Wien. Mus. 2:107 (1838); Endl., Gen. Plant. n. 6726.

Gênero com cerca de 30 espécies distribuídas, na América Tropical (Ducke 1949.). No Brasil foram encontradas 27 espécies e 7 variedades, sendo que a maioria encontra-se na Amazônia (Mattos 1979a).
Do tupi, andira $=$ morcego, referindo-se aos frutos que servem de alimento a esses animais (Barroso et al. 1991).

Hymenolobium Benth., J.Linn. Soc. 4:84, Suppl.(1860)

Estabelecido por Bentham (1876), a partir de H. nitidum Benth., da Amazônia, o gênero conta com 17 espécies, distribuídas pela região tropical, sendo que apenas uma alcança a região subtropical. Suas espécies são conhecidas pelo nome vernacular de "angelim", nome dado, também, a Andira e Vatairea, com os quais apresenta grande afinidade (Mattos 1979b). Todas as espécies do gênero Hymenolobium são largamente comercializadas por serem árvores de grande porte, que fornecem madeira dura e resistente. Podem ser ainda usadas como ornamental, devido ao aspecto magnífico que apresentam, por ocasião da floração, cobrindo-se de flores, que variam do lilás ao rosa-claro e raramente branco, de acordo com a espécie.

O nome do gênero refere-se aos lobos unidos do cálice (Barroso $t$ al 1991).

Vatairea Aubl., Hist. Pl. Guian. 2:755 t. 302. 1775; A.P. De Candolle, Prodr. 2:521. 1825; Ducke Archiv. Jard. Bot. Rio de Janeiro 3:153. 1922; idem, 1.c. 5:137. 1930; Amshoff, Fl. Suriname 2(2):121. 1939; Macbride, Publ. Field. Mus. Nat. Hist. Bot. Ser. 13(3):273. 1943; Pittier, Bol. Tec. Min. Agric. Cria 5:89. 1944; Standley et Steyermark, Fieldiana Bot. 24(5):360. 1946; Hutchinson, Gen. Flow. Pl. 1:387. 1967.

Gênero com cerca de oito espécies, distribuídas na faixa neotropical, estendendo-se desde o Sul do México até o Sudeste do Brasil. O centro de dispersão do gênero está situado nas regiões florestais da Amazônia Central. O nome do gênero refere-se a um nome popular utilizado na Guiana (Barroso et al 1991).

Os gêneros Andira, Hymenolobium e Vatairea formam um grupo intimamente relacionado (Lima 1980), mas particularmente complexo (Doyle et al. 2000). Para Lima (1980) a morfologia das flores e frutos e o progressivo crescimento da bainha estaminal, associado com a superposição das peças da carena, são características úteis na separação desses gêneros. Polhill (1981) reuniu tais gêneros e mais Vataireopsis em um único grupo (Grupo Andira) pela indeiscência do fruto e dureza do endocarpo, entretanto Doyle et al. (2000) quando apresentou um resumo de estudos de seqüenciamento $r c b \mathrm{~L}$ dos gêneros, indicou Vatairea como um grupo mais próximo de Luetzeburgia (Sophoreae) que de Andira. Para Doyle et al. (2000) Hymenolobium, Vatairea e Vataireopsis são um grupo e Andira outro.

\section{Chave para as espécies comercializadas no Estado do Pará como angelim}

1- Folha bipinada; casca com desprendimento em grandes placas (50 cm de compr. ou mais); não perde as folhas a florescer, inflorescência espiciforme; fruto legume samaróide, oblongo 2. Dinizia excelsa 


\section{ACTA AMAZONICA}

1'- Folha pinada; casca com desprendimento de placas pequenas ou médias (sempre menos que $50 \mathrm{~cm}$ de compr.); árvores geralmente desfolhadas no período fértil; inflorescência em heterocládio duplo racemo; fruto nunca legume samaróide.

\section{2- Até 10 folíolos}

3- Folíolos 7-9, opostos; ausência de papilas na face superior do folíolo; ovário oblongo-elíptico com paredes espessas; fruto drupáceo, ovoide

\section{Andira surinamensis}

3'- Folíolos 5-9, alternos; face superior do folíolo provida de papilas; ovário subfalcado com paredes finas; fruto sâmara, com expansões aliformes sobre o núcleo seminífero

\section{Vatairea paraensis}

\section{2'- Mais de 10 folíolos}

4. Folíolos com base retusa ou levemente truncada, ápice obtuso ou levemente emarginado, não mucronado e nem retuso

5. Folíolos $23-47,0,5-2,5 \mathrm{~cm}$ compr. $\mathrm{x}$ 0,3-0,8cm larg., armados; pubescência curta e esparsa na face superior e tomentosa na inferior; cálice com tricomas dispersos, com lobos bem evidentes e tufos de tricomas no ápice; suturas do ovário denso-pubescentes 3. H. excelsum

5'. Folíolos 11-22, 1,7-7,1cm compr. x 0,7-3,0cm larg., todos pendentes na ráquis; glabros na face superior $\mathrm{e}$ adpressamente pilosa na inferior; cálice glabro a raríssimo pubescente, com lobos discretos ou mesmo não evidentes, glabro; ovário com pubescência rara nas suturas e mais concentradas na base

\section{H. modestum}

4'. Folíolos com base cuneada ou obtusa, ápice emarginado ou levemente emarginado, mucronado e retuso

6. Folíolos 9-21 (2-7cm compr. x 1,1-3cm larg.), glabros na face superior, esparso-pubescentes na inferior; ramos glabros ou esparso-pubescentes; estípulas glabras; cálice raro pubescente; tufos de tricomas no ápice dos lobos; ovário glabro ou raríssimo pubescente 5 . H. petraeum

6'. Folíolos 15-29 (1-6,2cm compr. x 0,6-2,2cm larg.), glabrescentes na face superior e tomentosos na inferior; ramos e estípulas extremamente pubescentes; cálice densamente dourado-tomentoso, tricomas regularmente distribuídos nos lobos; ovário densamente pubescente

\section{H. pulcherrimum}

\section{Descrições das espécies}

1. Andira surinamensis (Bondt) Splitg. ex Amshoff in Meded. Bot. Museum \& Herb. Rijks Univ. Utrecht 52: 60. 1939. (Fig. 1).

Holótipo: Suriname. Bondt $s / n$ (L).

Árvore ou arbusto, $4-42 \mathrm{~m}$ alt., $56-181 \mathrm{~cm}$ DAP; tronco reto e cônico; base digitada; ritidoma marrom-acinzentadoclaro, estriado a fissurado superficialmente, desprendendose em pequenas placas cartáceas; casca morta marrom, fina
(>1 $\mathrm{mm})$; casca viva róseo-alaranjada, $4 \mathrm{~mm}$ espessura, exsudando resina incolor de odor forte, que oxida e fica alaranjada; alburno branco. Folha imparipinada, 15,0-26,0 cm compr.; gemas na base do pecíolo; estípulas caducas, 1,3$2,0 \mathrm{~mm}$ compr., pubescente; estipelas caducas, $1,0-3,0 \mathrm{~mm}$ compr., lanceoladas, pubescentes; pecíolo $3,2-4,8 \mathrm{~cm}$ compr., base dilatada, pubescente; raque subcilíndrica a canaliculada, estriada, pubescente. Folíolos 7-9 com 2,4-12,2 cm compr., 1,1-5,7 cm larg., oblongos, elípticos, suborbiculados ou ovados, opostos, subcoriáceos; ápice obtuso, emarginado ou retuso; base arredondada, margem ligeiramente recurvada; face superior glabra, com nervura mediana impressa ou subimpressa; face inferior pubescente, com nervuras mediana e secundárias proeminentes; peciólulos 3,0-4,0 mm compr. Inflorescência em heterocládio duplo racemo pubescente, terminal ou ocasionalmente axilar, $11-28 \mathrm{~cm}$ compr.; brácteas $2 \mathrm{~mm}$ compr., esparso-pubescentes; pedicelo $2,0-4,0 \mathrm{~mm}$ compr.; bractéolas $1 \mathrm{~mm}$ compr., curto-pubescentes. Flor 15$17 \mathrm{~mm}$ compr., róseo-violácea a violácea; cálice campanulado, 6,0-8,0 mm compr., pubescência marrom-avermelhada externamente, lobos agudos ou ocasionalmente obtusos;

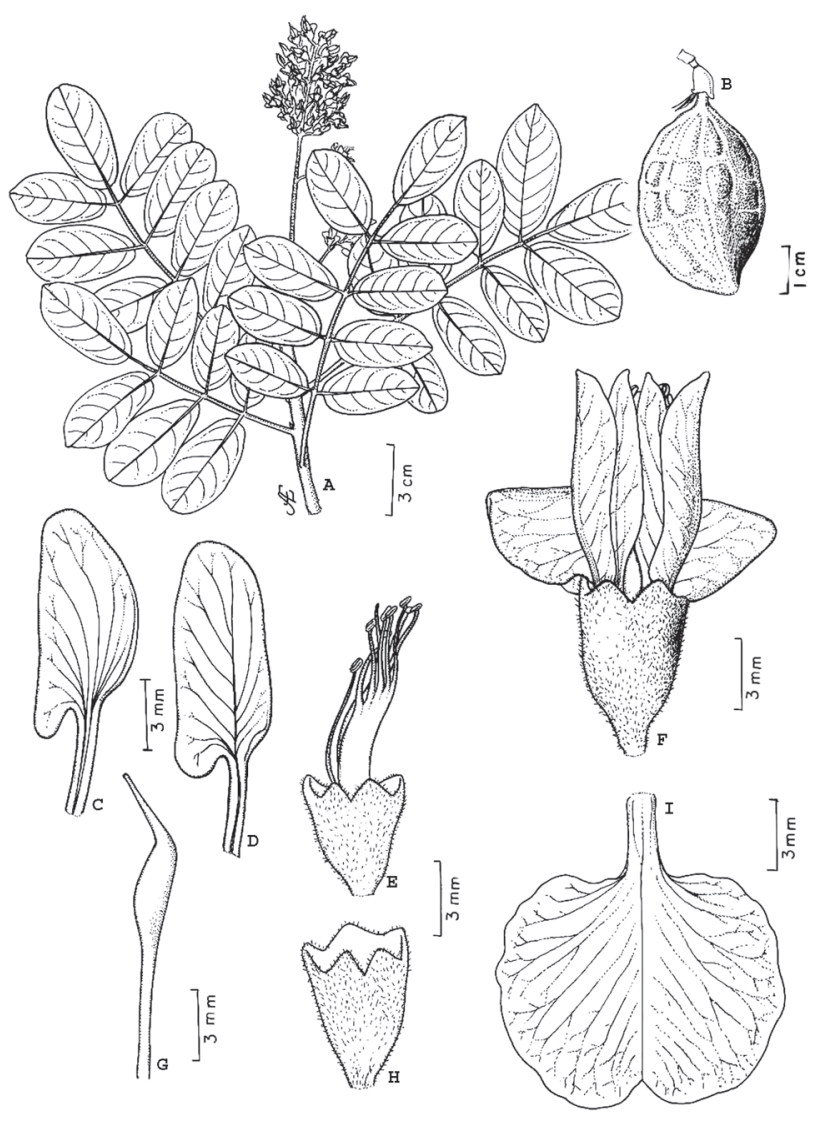

Figura 1 - Andira surinamensis (Bondt) Splitg. ex Amshoff - A) ramo com inflorescência; B) fruto evidenciando cálice e androceu persistentes; C) peça da carena; D) peça da ala; E) cálice e androceu; F) flor; G) gineceu; H) cálice; I) vexilo. A, C-I de J.M. Pires $\&$ N.T. da Silva 4224 (IAN); B de C.S. Rosário \& L.C.B. Lobato 1405 (MG). 


\section{ACTA \\ AMAZONICA}

CONTRIBUICCÃO AO CONHECIMENTO MORFOLÓGICO DAS ESPÉCIES

DE LEGUMINOSAE COMERCIALIZADAS NO ESTADO DO PARÁ, COMO "ANGELIM" corola arroxeada a lilás-violácea; vexilo 11-14 mm compr., 6,0-8,0 mm larg.; alas 11-14 $\mathrm{mm}$ compr., $4 \mathrm{~mm}$ larg.; peças da carena 11-14 mm compr., $3 \mathrm{~mm}$ larg.; estames 10 , diadelfos, 11-14 mm compr., heterodínamos; antera basifixa, biteca, deiscência longitudinal; gineceu 12-14 mm compr. e $15 \mathrm{~mm}$ larg., esparsamente pubescente; estígma curto, 3,04,0 mm compr.; ovário glabro, unilocular, 4-5 óvulos. Fruto drupa, 4,5-6,8 cm compr, verde-amarelado ficando enegrecido quando seco, cálice e androceu persistentes na base do fruto.

Áreas de ocorrência na Amazônia brasileira (Fig. 8): Acre: Rio Branco. Amapá: rio Araguarí. Amazonas: Tefé (rio Curimitá), margem do rio Marapi. Maranhão: estrada São Luiz-rio Anil, Itapicuru, Vitória do Mearim (rio Mearim). Pará: Almeirim (Cova da Onça), Belém (reserva Mocambo), Colares, Faro (fazenda Sta. Olímpia), Jacundá (Jatobal, rio Tocantins), Muaná (fazenda Cumaru e fazenda Maçaranduba), Óbidos, região do Jari (Água Branca-Km 12), Santarém (Barreirinha, rio Curuá-una), Vigia. Rondônia: vila Rondônia, Vilhena. Roraima: Br-401 (Km 81), rio Uraricoera (cachoeira Urubu). Ocorre freqüentemente em campos de várzea alta ou margens de rios e lagos ou como árvore isolada em savanas. É muito comum em áreas com vegetação secundária.

Nomes vernaculares: Acapurana (AC), andira, andiráuxi (AP), angelim, angelim-coco (AC), angelim-da-várzea (AM, AP, PA), angelim-doce (AC), angelim-vermelho (AC), axirana, cumarurana, fava-amargosa (PA), faveira, lombrigueira, lombrigueiro, morcegueira, morcegueiro, uchírana, uxi-de-morcego, uxi-morcego, uchirana (Le Cointe 1934; Ducke 1949; Rodrigues 1989; Camargos et al. 2001).

Material examinado: BRASIL: Pará, Almeirim, Cova da Onça, 03/04/1984, N.T.da Silva 5249 (MG); Maracanã, ilha de Algodoal, 23/09/1993, fr, M.N. Bastos et al. 1405 (MG); Vigia, 15/10/1978, fr, L.O.A. Teixeira 36 (MG); São Geraldo do Araguaia, serra das Andorinhas, 10/07/1995, fl, I. Aragão \& M.N. Bastos 123 (IAN); rio Aripuns, 08/06/1952, fl, J.M. Pires \& N.T.da Silva 4224 (IAN).

Reconhecimento no campo: a consistência cartácea dos folíolos e o brilho na face superior são características que facilmente a diferenciam no campo das demais. Ao corte, a casca viva de cor alaranjada, bastante fibrosa também é muito útil na sua identificação.

Vários sinônimos são atribuídos a esta espécie. Ducke (1949) conservou o citado na Flora Brasiliensis (Andira retusa (Poir.) H.B.K.), visto que para ele há muitas divergências entre os autores quanto ao uso de nomes mais antigos. Le Cointe (1934), Mainieri \& Primo (1968) e Rodrigues (1989) também a tratam, em seus trabalhos, como A. retusa (Poir.) H.B.K.

Para Mattos (1979a), Lewis \& Owen (1989) e Salazar (1993) A. retusa é sinônimo de A. surinamensis (Bondt) Splitg. ex Pulle, nome este não corretamente publicado. Pennington (2003) a separou das espécies A. vermifuga, $A$. bumilis, A. galeottiana e A. macrocarpa, quanto ao tamanho de fruto, indumento e folhas, não aceitando as variedades anteriormente publicadas.
Rodrigues (1989) escreveu que a madeira de $A$. surinamensis é parecida com o "acapu", porém de cor avermelhada, possuindo fibras grossas, lenho duro e nodoso, bastante resistente à umidade, com frutos globosos e não comestíveis, o que talvez motiva muitas vezes a identificação da espécie em Vouacapoua. Para Salazar (1993), o fuste da árvore é semelhante ao de Dipteryx.

Para Mattos (1979b), Andira é muito semelhante a Hymenolobium quando se observa apenas o material florífero, pois a diferença principal reside no fruto e no aspecto geral da planta viva.

O decocto da casca, segundo Mattos (1979a), é vermífugo usado por comunidades de Roraima, como remédio para malária.

2. Dinizia excelsa Ducke, Arch. Jard. Bot. Rio de Janeiro, 3:76-77, t.4,1922. (Fig. 2).

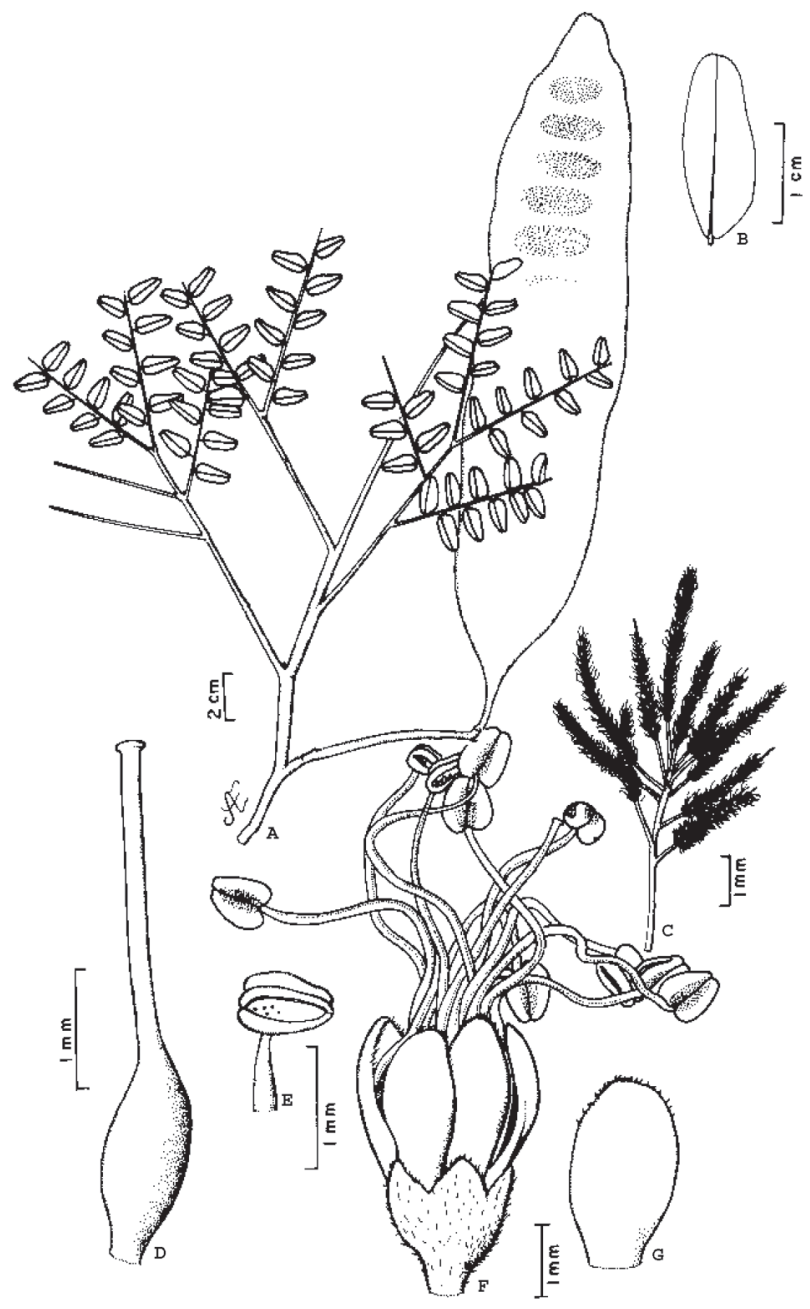

Figura 2 - Dinizia excelsa Ducke - A) ramo com fruto; B) foliólulo; C) ramo de inflorescências; D) gineceu; E) antera evidenciando deiscência; F) flor evidenciando cálice, corola e androceu; G) pétala evidenciando tricomas no ápice. A e B de N.T.da Silva 2947 (IAN), C-G de J.M. Pires et al. 5064 (IAN). 
Síntipos (lectótipo não designado): Brasil, Pará: Bela Vista, 6/12/1915, A. Ducke s/n, MG15826 (MG, RB); Cachoeira das Furnas, 26/06/1918, A. Ducke s/n, MG17073 (MG, RB); Oriximiná, 04/01/1914, A. Ducke s/n, MG15304 (MG) e 01/10/1915, A. Ducke s/n, MG15774 (MG); Gurupá, 25/01/1916, A. Ducke s/n, MG15989 (MG) e 16/5/1916, A. Ducke s/n, MG16177 (MG, RB).

Árvore medindo de 28-50 m alt., 79-575 cm DAP; tronco reto e cilíndrico; base com sapopemas até 1-2 $\mathrm{m}$ do solo; copa bem distribuída a muito larga; ritidoma com desprendimento em grandes placas vermelhas, com até $5 \mathrm{~cm}$ espessura, dando ao tronco aspecto escamoso, a parte interna de cor branco-amarelada, presença de resina incolor e inodora. Folha alterna, bipinada, imparipinada, 13,4-27,6 cm compr.; pecíolo 3,0-4,8 cm compr.; raque canaliculada, pubescente, com prolongamento terminal; pinas 6-10, de 3,7-7,9 cm compr., alternas; peciólulo 3-8 mm compr.; raque com pubescência curta e dispersa, canaliculada, com prolongamento terminal. Folíolos 10-20, com 11-25 mm compr., 5-10 mm larg., oblongos, sésseis; base assimétrica, ápice mucronado, margem inteira redobrada; face superior glabra ou raramente pubescente na nervura mediana, lustrosa; face inferior com pubescência escassa, nervura mediana discretamente proeminente. Inflorescência espiciforme; brácteas caducas, amarelo-pubescentes. Flor branco-esverdeada, pedunculada; cálice 1,5-1,9 mm compr., pubescente externamente, gamossépalo; pétalas livres, 3,5$4,0 \mathrm{~mm}$ compr., externamente pubescente, com aglomerados de tricomas no ápice das pétalas; androceu com estames livres, heterodínamos, exertos; antera dorsifixa, deiscência longitudinal, extrorsa, biteca; gineceu 3,8-5,5 mm compr., gamocarpelar; ovário externamente pubescente, unicarpelar, bilocular. Legume samaróide oblongo, marrom-avermelhado, ficando marrom-opaco quando seco, 21-35 cm compr. e 4,2-7,7 cm larg., margens retas, polispérmico, monocárpico.

Áreas de Ocorrência na Amazônia brasileira (Fig. 8): Amapá: Macapá, Mazagão, Serra do Navio. Amazonas: Balbina, Borba (baixo rio Madeira, Axinim), Boa Vista, Lábrea, Manaus-Itacoatiara, Manaus-Caracaraí, Manaus (Reserva Ducke, distrito Agropecuário da SUFRAMA), Maués, Parintins, Santa Isabel do rio Negro. Maranhão: rio Maracassumé. Pará: Almeirim, Alto Tapajós (Vila Nova), baixo Tocantins, Breves, Curuá-Una, estrada Belém-Brasília (Km 201, 195, 234, 129), Gurupá, Jacundá, Moju, Monte Dourado (rio Jari-igarapé Tinguelim), Melgaço; Prainha (rio Uruará), Porto Trombetas, Porto de Moz (rio Jaraucu), rio Curuatinga, rio Una (Planalto de Santarém), rio Tocantins (igarapé São Miguel), rio Xingu (entre Vitória e Altamira), Tucuruí, Santarém, Santa Bárbara. Rondônia: Porto Velho, Santa Bárbara, Santo Antônio, Teotônio. Roraima: Boa Vista, São João da Baliza. Habita preferencialmente terrenos sílicoargilosos, às vezes forma pequenos grupos ou manchas de indivíduos (Mekdece et al. 1999).

Nomes vernaculares: Angelim (PA, AM, AP), angelimfalso (PA), angelim-ferro (PA), angelim-pedra (AM, AC), angelim-vermelho (PA), dinízia-parda (PA), faveira (PA, AC; $\mathrm{AM}, \mathrm{AP}$ ), faveira-dura (PA), faveira-ferro (PA), faveira-grande (PA), faveira-preta (PA).

Material Examinado: BRASIL: Pará: Km 201 da rodovia Belém-Brasília, 14/05/1960, fl, E.de Oliveira 755 (IAN); Km 201 da rodovia Belém-Brasília, 15/05/1960, fr, E.de Oliveira 757 (IAN); rio Jari, igarapé Tinguelim, 16/08/1969, fl N.T.da Silva 2703 (IAN); rio Jari, Monte Dourado, 18/06/1968, fr, E.de Oliveira 4562 (IAN); rio Jari, 09/09/1968, fl, N.T.da Silva 911 (IAN); rio Jari, 10/05/1970, fl, N.T.da Silva 3128 (IAN).

Reconhecimento no campo: É uma das maiores árvores da floresta amazônica e dificilmente é confundida com outras espécies pelo desprendimento do ritidoma em placas grandes, lenhosas e irregulares que formam amontoados na base do tronco que deixam cicatrizes mais claras que a casca morta. O tronco apresenta alguma semelhança com Parkia pendula e Enterolobium schomburgkii pelo desprendimento em placas do ritidoma, porém nestes não há amontoados na base. A forma falcada do folíolo em Dinizia excelsa pode confundir com espécies de Zygia e Dimorphandra, mas diferencia-se por apresentar glândulas no pecíolo e a forma geral da árvore e partes reprodutivas são muito diferentes.

3. Hymenolobium excelsum Ducke in Arch. Jard. Bot. Rio de Janeiro, I (38), 1915 (Fig. 3)

Síntipos (lectótipo não designado): Brasil, Pará: Alcobaça, rio Tocantins, 28/12/1914, A. Ducke s/n, MG15559 (MG, RB); Belém, 31/03/1915, A. Ducke s/n, MG15664 (MG, RB); Oriximiná, 27/02/1915, A. Ducke, s/n MG15695 (MG, RB).

Árvore de grande porte, 30-45 m alt., 90,1-149,5 cm DAP; tronco reto e cilíndrico; base digitada ou com sapopemas de 70-250 cm do solo, côncavas; ritidoma marromacinzentado, com marcas digitadas, amareladas, deixadas pelo desprendimento em pequenas placas irregulares, marrom-avermelhadas, coriáceas; lenticelas proeminentes, grandes $(>1 \mathrm{~cm})$, vermelhas, espocadas, dispersas; casca morta marrom-escura, até $2 \mathrm{~mm}$ espessura, pétrea, aspecto de cortiça; casca viva marrom-avermelhada, até $2 \mathrm{~cm}$ espessura, com linhas verticais, finas, vermelho-escuras; exsuda resina vermelha e pegajosa; alburno brancoamarelado com linhas alaranjadas. Folha disposta nos ápices dos ramos, alterna com aspecto de verticilada, imparipinada, 9,0-13,5 cm compr.; ramos com cicatrizes deixadas pelas folhas caídas; estípulas lanceoladas, pilosas; pecíolo 1,6-3,0 cm compr.; raque canaliculada, pubescente. Folíolos 23-47, com 0,5-2,5 cm compr., 0,3-0,8 cm larg., opostos; base retusa ou truncada; ápice discretamente emarginado, mucronado, margem recurvada; face superior com pubescência curta, esparsa, nervura mediana impressa; face inferior tomentosa, com nervura mediana proeminente; peciólulos $>1 \mathrm{~mm}$ compr., pubescentes. Inflorescência terminal, heterocládio duplo racemo, flavo-tomentosa; brácteas pubescentes, 14 mm compr., caducas; bractéolas, ca. $11 \mathrm{~mm}$ compr., pubescentes, caducas. Flor 13-18 mm compr.; pedicelo 2,04,0 mm compr., cilíndrico, pubescente; cálice campanulado com dentes bem evidentes, vináceo, pubescente, amarelo- 


\section{ACTA \\ AMAZONICA}

CONTRIBUICCÃO AO CONHECIMENTO MORFOLÓGICO DAS ESPÉCIES

DE LEGUMINOSAE COMERCIALIZADAS NO ESTADO DO PARÁ, COMO "ANGELIM" ferrugíneo externamente, com tufos no ápice dos dentes, 6-8mm compr.; corola róseo-arroxeada, pálida; vexilo 12 $14 \mathrm{~mm}$ compr.; alas 13-14 mm compr.; peças da carena 12$13 \mathrm{~mm}$ compr.; estames 10, heterodínamos, monadelfos, 10-12 mm compr.; concrescidos até $2 / 3$ do comprimento; antera basifixa, deiscência longitudinal, extrorsa, biteca, 2 $\mathrm{mm}$ compr., $1 \mathrm{~mm}$ larg.; gineceu 18-20 mm compr., gamocarpelar, unicarpelar; ovário unilocular, densamente ferrugíneo-pubescente nas suturas. Sâmara bege-clara a marrom-escura, 10,1-19,2 cm compr., 2,3-3,5 cm larg., apículo terminal semi-caduco, oblonga, núcleo seminífero central e pouco distinto das alas, nervuras laterais, paralelas, uma indo da base até o ápice, a outra até $2 / 3$ do comprimento, proeminentes, deixando a superfície rugosa, cálice e androceu persistentes. Sementes 1-2.

Áreas de Ocorrência na Amazônia brasileira (Fig. 8): Amapá: Serra do Navio. Amazonas: Parintins, rio Uaupés.

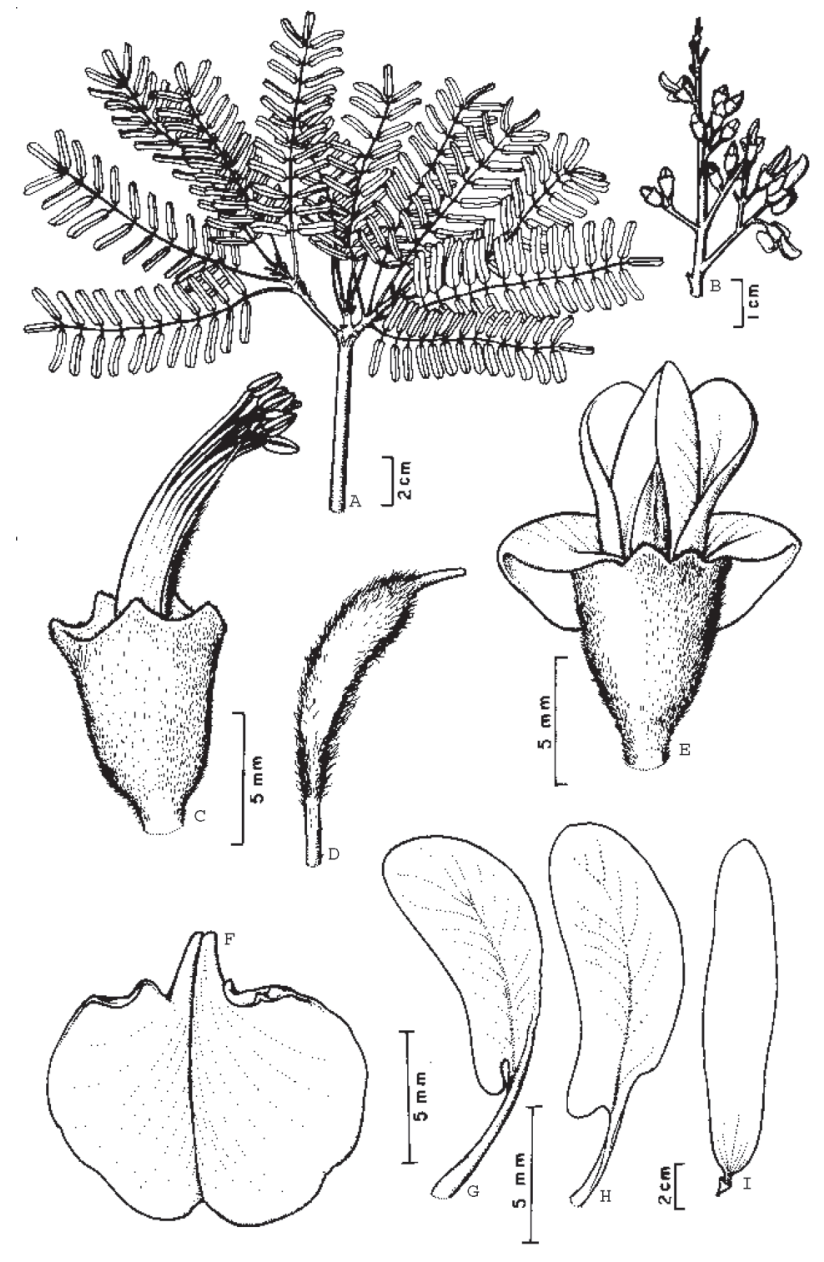

Figura 3 - Hymenolobium excelsum Ducke - A) ramo evidenciando disposição das folhas; B) inflorescência; C) flor evidenciando cálice e androceu; D) gineceu; E) flor evidenciando corola; F) vexilo; G) peça da carena; H) peça da ala; I) fruto. A-H de N.T.da Silva 2906 (IAN), I de A. Ducke 1680 (IAN).
Pará: Alcobaça (Tocantins), Baixo e Médio rio Trombetas (Oriximiná, Lago Erepecuru, rio Acapu), Belém, Bragança, Breu Branco, Cachoeiras inferiores do Tapajós, Faro, Ilhas altas do Tajuparu (Breves), Melgaço (Caxiuanã), Moju, Monte Dourado, Paragominas (fazenda Cikel), Santarém (Serra), Tailândia, Tucuruí. Encontrada geralmente nas matas altas de terra firme do Pará. Vai desde o Atlântico até a parte oriental do Amazonas (Parintins).

Nomes vernaculares: Angelim (AM), angelim-comum (AC, PA), angelim-da-mata (PA), angelim-rajado (AC, RO, RR), angelim-rajado-da-mata (AC, RR), fava-folha-fina (AM, AP).

Material Examinado: BRASIL: Amazonas, Parintins, Macorany, 04/01/1936, fl, A. Ducke s/n (RB); rio Uaupés, 18/11/1987. Pará, Belém, 22/04/1947, fl, J.M. Pires \& G. Black 1513 (INPA, RB); Instituto Agron. Norte, 14/12/1950, fl, J.M. Pires 2676 (INPA); ibdem 18/04/1947, fl, J.M. Pires E G. Black 1315 (INPA); ibdem, 14/12/1950, fr, J.M. Pires 2676 (IAN); Utinga, 26/10/1944, fl, 22/12/1944, fr, A. Ducke 1680 (IAN); mata da Quinta Carmita (rio Magoary), 11/1916, fl, fr, A. Ducke s/n (INPA, RB); rio Caxiuanã, 07/09/1983, fl, B.S. Pena 1022 (INPA).

Reconhecimento no campo: Hymenolobium excelsum apresenta numerosos folíolos muito pequenos, quando adulto, o que a torna bem diferente das demais espécies do gênero. Quando jovem, a árvore pode ser confundida $\operatorname{com} H$. beterocarpum e $H$. pulcherrimum pelo tamanho e pubescência da folha e folíolos, entretanto a morfologia do tronco a diferencia destes. A simetria dos ramos a faz uma das mais elegantes árvores da floresta amazônica. Durante o período de floração esta conserva alguns ramos com folhas, já os ramos floridos ficam completamente desprovidos de folhas.

4. Hymenolobium modestum Ducke in Arch. Jard. Bot. Rio de Janeiro I(1): 37, 1915; Lima, Acta Amaz. 12:46. 1982. (Fig. 4).

Lectótipo: Brasil, Pará, Óbidos, 16/03/1915, A. Ducke, s/ n, MG15725 (K, MG, RB).

Árvore, 35-46 m alt., 79,1-109,8 cm DAP; tronco circular a cônico, reto; base com sapopemas de 2,5-3,0 m do solo, côncavas, algumas convexas, ramificadas; ritidoma marromavermelhado, rugoso, com fissuras horizontais e verticais rasas, desprendimento em placas pequenas, irregulares, coriáceas, que quando caem, deixam marcas digitadas, avermelhadas; lenticelas grandes $(>5 \mathrm{~mm})$, dispersas, proeminentes, avermelhadas; casca morta vermelhoamarronzada, com aspecto de cortiça, porosa; casca viva róseo-amarelada, escura, amarela próximo ao alburno, com fibras vermelhas, porosa, exsudando resina vermelha pegajosa. Folha imparipinada 9,0-22,3 cm compr., disposta no ápice dos ramos, alterna com aspecto de verticilada; estípulas lanceoladas, 5,0-6,5 mm compr., pubescentes; estipelas $>1 \mathrm{~mm}$ compr., pubescentes, falciformes; pecíolo 2,8-5,6 cm compr., subcilíndrico, enrrugado, curto ou raropubescente; raque canaliculada, enrugada, pubescente/ tomentosa. Folíolos 11-22 com 1,7-7,1 cm compr., 0,7-3,0 cm larg., subcoriáceos a cartáceos, oblongos a obovados, 


\section{ACTA AMAZONICA}

CONTRIBUIÇÃO AO CONHECIMENTO MORFOLÓGICO DAS ESPÉCIES

DE LEGUMINOSAE COMERCIALIZADAS NO ESTADO DO PARÁ, COMO "ANGELIM" opostos, às vezes ocorrendo sub-alternos, ápice arredondado, às vezes discretamente emarginado, mucronado, base arredondada, obtusa ou truncada, às vezes aguda nos folíolos terminais; face superior glabra, levemente lustrosa, com nervura mediana impressa; face inferior adpressamente pilosa, amarelo-avermelhada, com nervura mediana proeminente, pubescente; peciólulo glabro a subglabro, sub-cilíndrico, 3,0-3,5 mm compr. Inflorescência em heterocládio duplo racemo, 5,5-10 cm compr., tomentosas; brácteas tomentosas, $1 \mathrm{~mm}$ compr.; bractéolas tomentosas, menores que $0,8 \mathrm{~mm}$ compr. Flor $15-18 \mathrm{~mm}$ compr., róseo a violácea; pedicelo 3,0-4,0 $\mathrm{mm}$ compr., pubescente, cilíndrico; cálice 5,0-6,0 mm compr., curtopubescente, dourado, campanulado, com dentes muito discretos, obtusos; corola membranácea, $18 \mathrm{~mm}$ compr.; vexilo unguiculado 14-16 mm compr., 9-10,5 mm larg.; alas e peças da carena 14-16 mm compr., 3,2-4,5 mm larg.; estames 10, monadelfos, 13,2-14,6 mm compr., concrescidos até $3 / 4$ do comprimento; antera dorsifixa, biteca, menos de 6,0 mm compr.; ovário longo-estipitado, pubescência nos bordos; estilete curvo, raramente pubescente na base; estígma punctiforme; 2-3 óvulos. Sâmara 9,9-13,7 cm compr., 2,7-3,8 cm larg., amarelo-acinzentada a marrom-

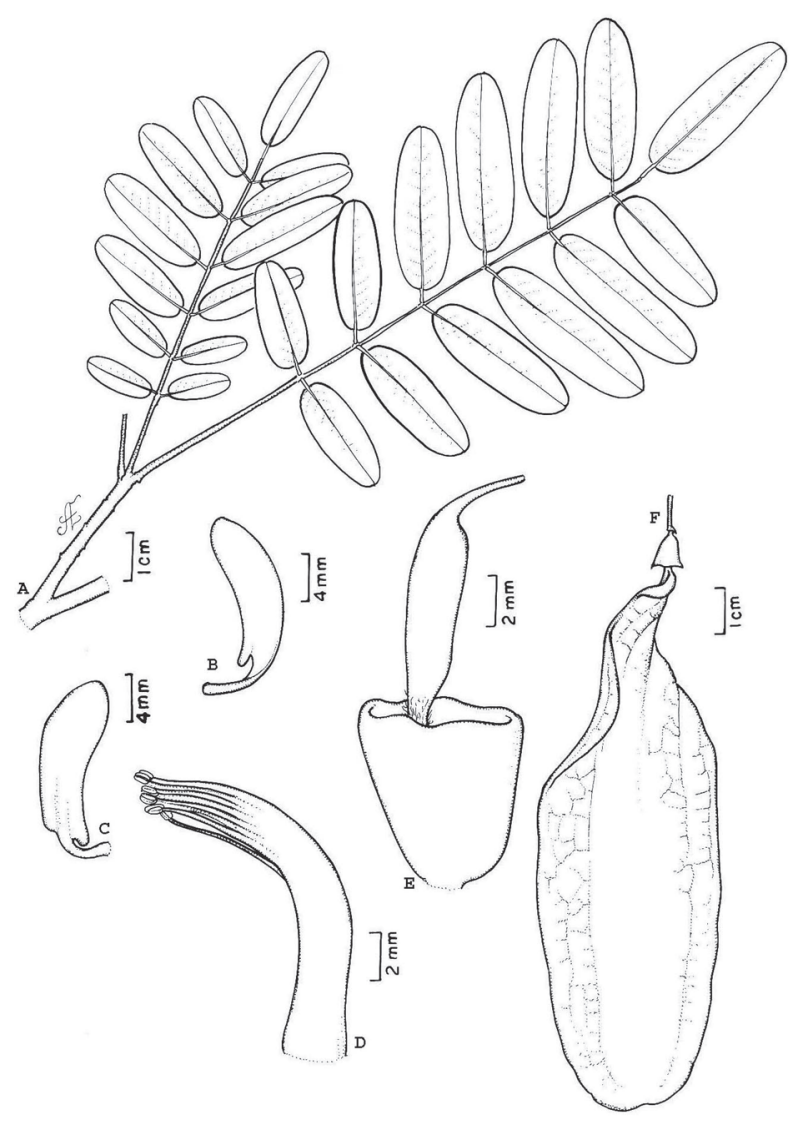

Figura 4 - Hymenolobium modestum Ducke -A) ramo com folhas; B) peça da carena; C) peça da ala; D) androceu; E) cálice e gineceu; F) fruto. A-E de A. Duckes/n (MG 16727); F de A. Ducke 1185 (MG 18221). avermelhada levemente coberta por cera esbranquiçada, oblonga, com apículo terminal; quando seca a nervação fica ondulada dando aspecto rugoso à superfície. Sementes 12, com 1,5-1,8 cm compr., 4,0-6,0 mm larg.

Áreas de Ocorrência na Amazônia brasileira: Amazonas (Fig. 8): Manaus, estrada de Joaquim Paulo, estrada do Aleixo, Km-5, rio Cuieiras, São Paulo de Olivença. Pará: Faro, Óbidos, Porto Trombetas. Apresenta ampla distribuição nas matas de terra firme da Amazônia brasileira. Ducke (1915) registrou a ocorrência da espécie em terreno arenoso de matas baixas, secundárias.

Nomes vernaculares: Angelim (AM, PA), angelimamarelo (PA), angelim-do-Pará (AM, AP, PA, RR).

Material Examinado: Brasil: Amazonas: Manaus, estrada de Joaquim Paulo, 30/01/1932, fl, A. Ducke s/n (RB23841). Pará: Porto Trombetas, entrada da barragem do Caranã, 13/03/1996, fr, S.M. de Faria et al., 1159 (RB).

Reconhecimento no campo: Quando adulta, Hymenolobium modestum pode ser facilmente diferenciada das demais pelas folhas que são mais coriáceas; os ramos pendentes é uma característica de fácil reconhecimento da espécie, apesar de que as folhas jovens de H. petraeum também apresentarem-se pendentes, porém a morfologia do tronco é diferente. Lima (1982a) separou $H$. modestum de $H$. flavum pelo fruto que é rígido-membranáceo, estreito-oblongo e a coloração dos folíolos é mais flavescente em $H$. flavum.

5. Hymenolobium petraeum Ducke, Arch. Jard. Bot. Rio de Janeiro, I (36), 1915. (Fig. 5)

Síntipos (lectótipo não designado): Brasil, Pará: Belém, 01/1915 (fol), 15/10/1914 (fl), 26/11/1914 (fr), A. Ducke s/ n, MG15504 (MG, RB); idem, 21/1/1915 (fl), 24/3/1915 (fr), 8/4/1915 (fol), A. Ducke s/n, 15661(MG, RB); Óbidos 16/2/ 1915 (est.), A. Ducke s/n, MG15723 (MG); Faro 17/2/1915 (fr), A. Ducke s/n, MG15674 (MG).

Árvore de grande porte, 30-40 m alt., 64-190 cm DAP; tronco reto e cilíndrico; tronco reto e cilíndrico; base digitada; ritidoma acinzentado, estriado, desprendimento em placas irregulares, espessas (até $1 \mathrm{~cm}$ ), marrom-acinzentadas, coriáceas, desprendendo-se de baixo pra cima; lenticelas proeminentes, vermelho-alaranjadas, espocadas; casca morta marrom-avermelhada, coriácea, até $2,5 \mathrm{~mm}$ espessura; casca viva vermelho-rosada, 2,0 cm espessura, porosa, fibrosa; exsuda resina vermelha, pegajosa; alburno amarelo. Folha disposta no ápice dos ramos, alterna, mais espaçadas que nas demais espécies, imparipinada, 10,9-16,8 cm compr.; estípulas lanceoladas, caducas, $8 \mathrm{~mm}$ compr., glabras, membranáceas; estipelas lineares ou falcadas, esparsopubescente, $1 \mathrm{~mm}$ compr.; pecíolo subcilíndrico, glabro, discretamente pubescente, 2,7-3,9 cm compr.; raque subcilíndrica a canaliculada, glabra. Folíolos 9-21, opostos e alternos no mesmo ramo, 2,0-7,0 cm compr., 1,1-3,0 cm larg., oblongos a obovados; ápice retuso a curto-emarginado, mucronado, base cuneada; face superior glabra, verde-opaca a marrom-opaca quando seca, pubescência adpressa, rara, nervura mediana impressa, secundárias pinadas; face inferior 


\section{ACTA \\ AMAZONICA}

CONTRIBUICCÃO AO CONHECIMENTO MORFOLÓGICO DAS ESPÉCIES

DE LEGUMINOSAE COMERCIALIZADAS NO ESTADO DO PARÁ, COMO "ANGELIM" marrom-avermelhada, acinzentada, tomentosa, nervura mediana proeminente; peciólulos $2-4 \mathrm{~mm}$ compr., cilíndricos, pubescentes. Inflorescência heterocládio duplo racemo, tomentoso, 10-16,5 cm compr.; brácteas $4 \mathrm{~mm}$ compr.; bractéolas $>1 \mathrm{~mm}$, tomentosas, lanceoladas. Flor 15-22 mm compr.; pedicelo ferrugíneo, tomentoso, com tufo de tricomas no ápice; cálice 4-7 mm compr., campanulado, 5dentado, pubescente, tufos de tricomas no ápice dos dentes; corola róseo-lilás a violácea, membranácea; vexilo 17-22 mm compr.; alas 13-22 mm compr.; peças da carena 13-18 mm compr.; estames 10, com 11-12 mm compr., monadelfos, heterodínamos, concrescidos até $2 / 3$ do comprimento, glabros; antera dorsifixa, biteca, $>1 \mathrm{~mm}$ compr., deiscência longitudinal; gineceu 12-15 mm compr., gamocarpelar,

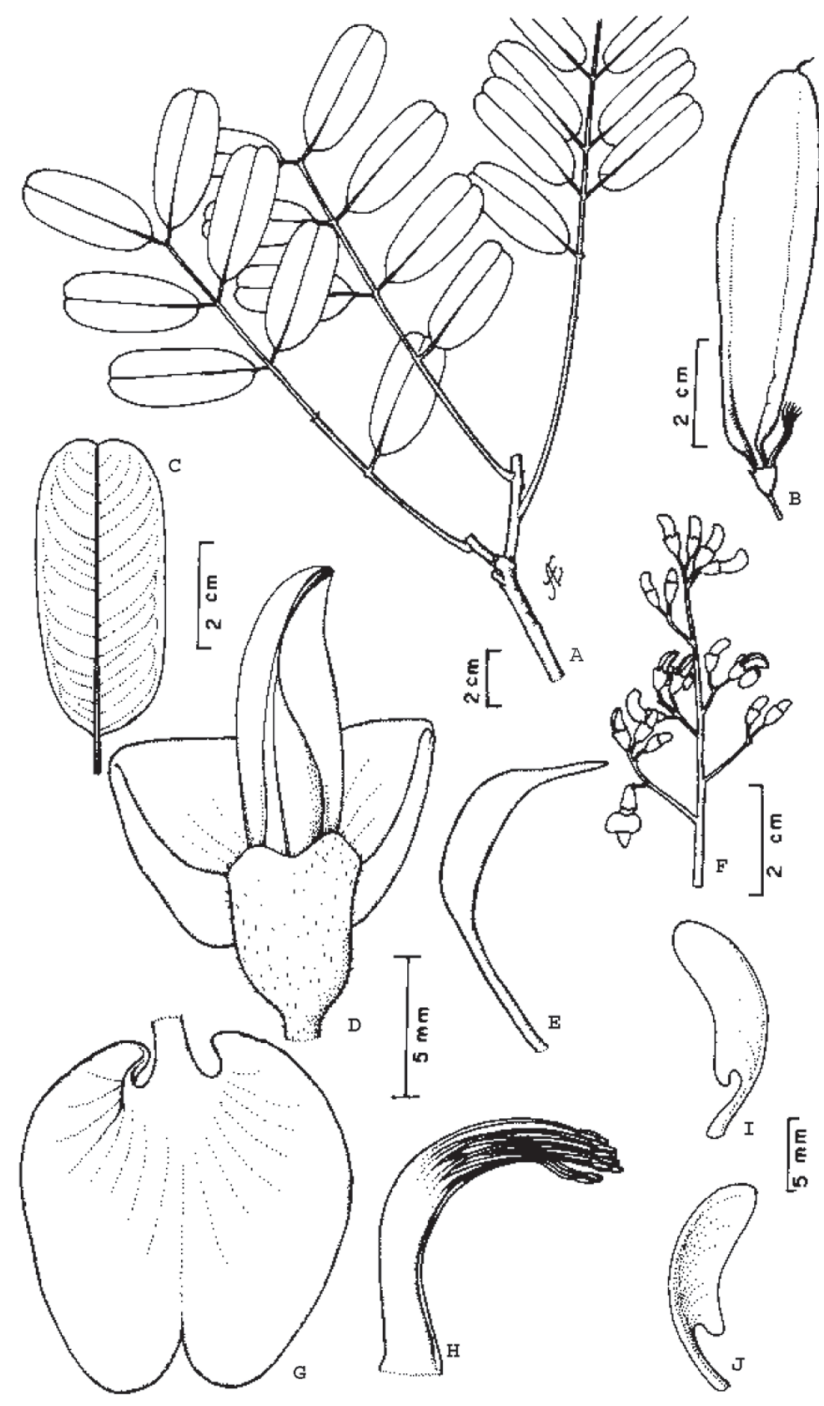

Figura 5 - Hymenolobium petraeum Ducke - A) ramo com folhas; B) fruto; C) folíolo; D) flor evidenciando corola; E) gineceu; F) inflorescência; G) vexilo; $\mathrm{H}$ ) androceu; I) peça da carena; J) peça da ala. A, C-J de A.Ducke s/ $n$ (IAN), B de J.M. Pires 1300 (IAN). unicarpelar; ovário pubescente nas laterais e até $1 / 3$ da largura, unilocular. Sâmara 4,5-10 cm compr., 1,1-2,3 cm larg., oblonga, achatada, com apículo terminal semi-caduco; cálice e androceu persistentes na base do fruto; nervuras laterais, paralelas, proeminentes, uma indo da base até o ápice e outra até $1 / 3$ do comprimento; pontos circulares, esbranquiçados, como fungos em toda a superfície do fruto. Sementes 1-2.

Áreas de Ocorrência na Amazônia brasileira (Fig. 8): Amapá: campo alto de Mazagão, Macapá, Serra do Navio. Amazonas: Manaus, Parintins. Maranhão: Itapicuru. Roraima: Ilha do Maracá. Pará: Abaetetuba, Almeirim, Belém, Bragança, estrada de Altamira a Oeste da volta do Xingu, Faro, Gurupá, Monte Alegre, Monte Dourado, Mosqueiro, Óbidos, região do Jari, rio Tapajós (Bela Vista), rio Xingu, Santarém (Serra). Roraima: ilha de Maracá. São geralmente encontradas em matas altas de terra firme do Pará e Amazonas, sendo encontrados ainda, nos campos altos do Amapá em tamanho menor que na terra firme.

Nomes vernaculares: Angelim (PA, AM), angelimamarelo (PA), angelim-aroeira (MA), angelim-branco-pedra $(\mathrm{PA}, \mathrm{AC})$, angelim-comum (PA), angelim-da-mata (PA), angelim-do-Pará (AM, PA, RR), angelim-grande (AM, PA, MA), angelim-macho (MA), angelim-pedra (PA), angelim-róseo (PA, AC), angelim-vermelho (AM), mirarema (MA), murarema (MA), sucupira-amarela (MA, RR).

Material Examinado: Brasil: Pará: Abaetetuba, Itacupé, estrada para vila de Beja, 01/09/2001, fl, G.C. Ferreira 727 (IAN); Belém, mata da Quinta Carmita (rio Magoary), 24/12/1922, fl, A. Ducke s/n (RB); Mosqueiro, praia do Murubira, 21/01/1923, fr, A. Ducke s/n (RB); Utinga, 11/1948, fl, A. Ducke, s/n (IAN); margens do açude do Catú, 1948, fl, A. Lima 26 (RB); Monte Dourado, rio Jari, 23/10/1968, fl, fr, N.T.da Silva 1298 (IAN); região do Jari, estrada do Caracurú, 04/10/1969, fr, N.T.da Silva 2811 (IAN). Roraima: ilha de Maracá, G.P. Lewis $s / n$, fr, (RB 330854), s/d, W. Williken s/n, fr, (INPA 167283).

Reconhecimento no campo: $\mathrm{O}$ aspecto geral da árvore, principalmente, tamanho dos folíolos (bem maiores que nas demais), pubescência rara ou ausente nos ramos e folhas, e desprendimento da casca externa/ritidoma em grandes placas retangulares e extremamente coriáceas a diferencia das demais espécies estudadas. No período de floração e frutificação a árvore fica desprovida de folhas, sendo a morfologia do tronco a mais útil característica para seu reconhecimento, principalmente a ausência de sapopemas que ocorrem em $H$. modestum e $H$. pulcherrimum.

6. Hymenolobium pulcherrimum Ducke, Archiv. Jard. Bot. Rio de Janeiro, 1:37 (1915) (Fig. 6)

Holótipo: Brasil, Pará, Faro, 18/02/1915, A. Ducke, s/n, MG15676 (MG, RB).

Árvore, 35-42 m alt., 71-90 cm DAP; tronco reto; base com sapopemas até 1,20 m do solo, ramificadas; ritidoma marromescuro, reticulado, com lenticelas esparsas; casca morta escura, com marcas tipo chamas, até $1 \mathrm{~mm}$ espessura; casca viva alaranjada $4 \mathrm{~mm}$ espessura, odor característico de legume; alburno amarelo. Folhas aglomeradas no ápice dos ramos, mas 


\section{ACTA AMAZONICA}

CONTRIBUIÇÃO AO CONHECIMENTO MORFOLÓGICO DAS ESPÉCIES

DE LEGUMINOSAE COMERCIALIZADAS NO ESTADO DO PARÁ, COMO "ANGELIM" regularmente dispostas, imparipinadas, 9,5-26 cm compr; estípulas na base das folhas densamente cinza-amareladas, pubescentes externamente, $7-15 \mathrm{~mm}$ compr.; estipelas lineares/ falciformes, pubescentes, 1-4 mm compr.; pecíolo 3,2-5,6 cm compr., subcilíndrico, dilatado na base; raque canaliculada, tomentosa. Folíolos 15-29, com 1,0-6,2 cm compr., 0,6-2,2 cm larg., opostos, oblongos; ápice obtuso ou ligeiramente retuso, base obtusa ou arredondada; face superior com pubescência esparso-acinzentada, curta, nervura mediana levemente impressa, as secundárias pinadas; face inferior com pubescência curta, dourada (tomentosa), nervura mediana proeminente, as secundárias pouco evidentes; peciólulos 2,0-3,0 mm compr., canaliculados, tomentosos. Inflorescência terminal em heterocládio duplo racemo, 9,2-27,2 cm compr.; raque e pedicelos densamente tomentosos; brácteas tomentosas, $5 \mathrm{~mm}$ compr., lanceoladas; bractéolas tomentosas, 1-2 mm compr., falciformes. Flor 14-18 mm compr.; pedicelo pubescente ou tomentoso, 4-7 mm compr., cilíndrico; cálice 4-8 mm compr., 5-dentado, densamente dourado-tomentoso externa e internamente, campanulado; corola róseo-pálida a vinácea,

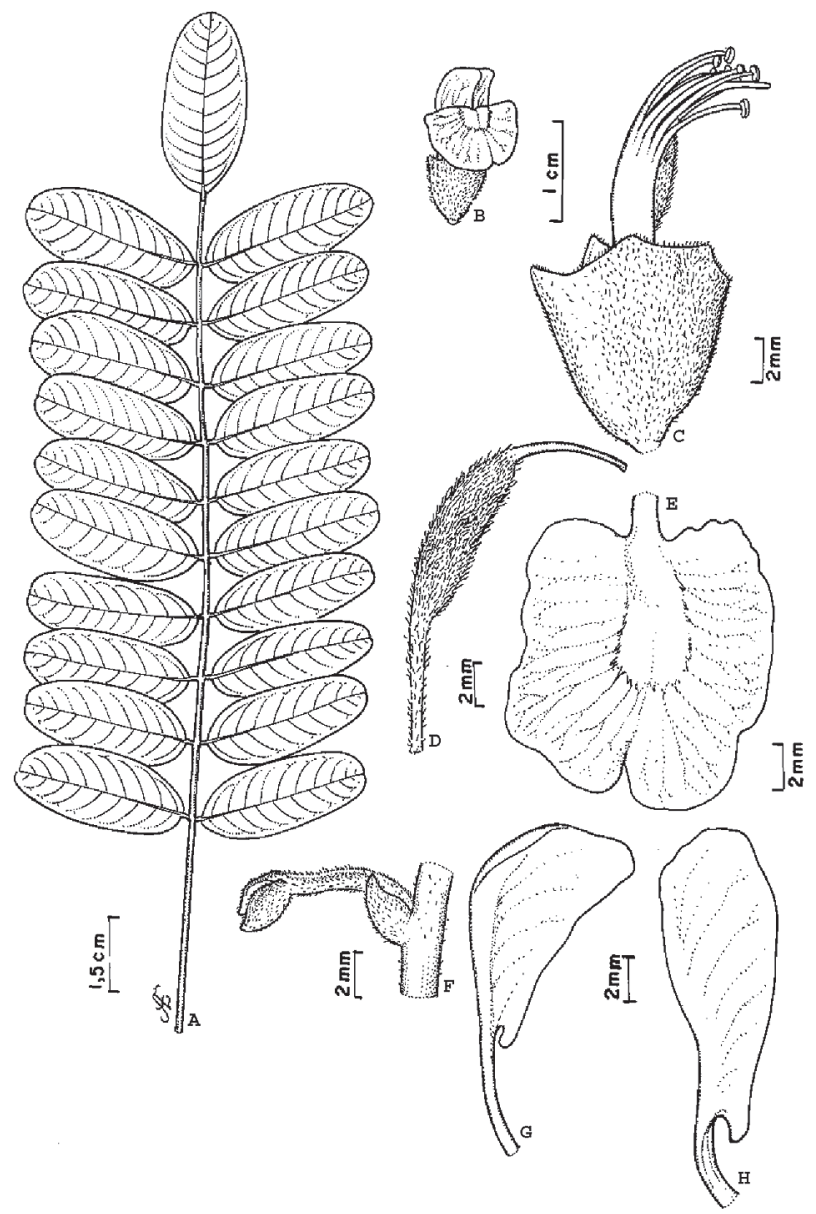

Figura 6 - Hymenolobium pulcherrimum Ducke - A) folha; B) flor; C) cálice e androceu; D) gineceu; E) vexilo; F) detalhes da estipela; G) peça da ala; $\mathrm{H})$ peça da carena. A e H de W.A. Rodrigues 8014 (INPA); B-G de G.S. Hartshorn 1843 (IAN). membranácea; vexilo $17-20 \mathrm{~mm}$ compr.; ala e carena $19 \mathrm{~mm}$ compr.; estames 10 , concrescidos até $3 / 4$ do comprimento, monadelfos, glabros; antera dorsifixa, deiscência longitudinal, biteca, extrorsa, 0,9 mm compr.; gineceu 19-20 mm compr.; ovário longo, pubescente nas laterais (suturas), unilocular; estilete curvo, glabro; estigma circular. Sâmara 9,4-17 cm compr., 1,6-4,1 cm larg., oblonga, superfícies cobertas por cera esbranquiçada, cálice e androceu persistentes na base; nervuras laterais paralelas, uma indo da base até o ápice, a outra até $3 / 4$ do comprimento, ápiculo terminal caduco. Semente 1.

Áreas de ocorrência na Amazônia brasileira (Fig. 8): Amazonas: Manaus (estrada Manaus-Itacoatiara, reserva florestal Ducke), Parintins, rio Canumã. Pará: Baixo Trombetas, Faro, Gurupá, lago do Moura, Volta do Xingu. Rondônia: Itapuã do Oeste (Floresta Nacional do Jamari). Loureiro et al. (1997) relataram que a espécie ocorre no estado do Amazonas (Parintins, Borba - baixo rio Madeira) e que é rara nas matas de terra firme do Pará; porém é, freqüentemente encontrada nos arredores do lago do Moura, a oeste do baixo Trombetas. Foi coletada recentemente em mata de terra firme no município de Moju.

Nomes vernaculares: Angelim ( $\mathrm{PA}, \mathrm{AM})$, angelim-amarelo (AM, AC), angelim-catinguento (PA), angelim-da-mata (AM, AP, PA), angelim-do-pará (AM, PA, RR, RO), angelim-pedra (AC, PA), sapupira-amarela (MA, RO, RR) (Camargos et al. 2001; Ducke 1949; Mattos 1979b; Loureiro et al. 1997).

Material examinado: BRASIL: Amazonas, Borba, rio Madeira, 17/01/1930, fr, A. Ducke s/n (RB); Reserva Florestal Adolfo Ducke, 11/12/1997, fl, P.A.C.L. Assunção et al. 750 (INPA, RB); ibdem, 01/10/1997, fl, P.A.C.L. Assunção et al. 688 (INPA, RB); estrada do Aleixo, 30/01/1936, fr, A. Ducke $s / n$ (RB); estrada da vila Bilisário Pena, 26/12/1929, fl, A. Ducke s/n (RB); mata de terra firme a leste de Flores, 10/02/ 1933, fl, A. Ducke s/n (RB); Parintins, lago José-Assu, 27/12/ 1935, fl, A. Ducke s/n (RB). Pará, Faro, 18/02/1915, fr, A. Ducke s/n (RB 5578); rio Xingu, estrada de Volta perto de Victória, 12/12/1916, fr, A. Ducke s/n (MG, RB).

Reconhecimento no campo: As folhas de Hymenolobium pulcherrimum podem ser confundidas com folhas jovens de $H$. excelsum, pelo tamanho, forma e pubescência, porém o ritidoma reticulado com anéis em volta de todo o tronco a difere de $H$. excelsum onde o ritidoma é geralmente estriado em indivíduos jovens. A copa fica completamente desprovida de folhas durante a floração e frutificação, sendo as características do tronco muito úteis no seu reconhecimento. A madeira quando cortada e passado alguns dias exala odor forte e desagradável que a faz ser rejeitada por compradores.

7. Vatairea paraensis Ducke in Archiv. Jard. Bot. Rio de Janeiro, 138 (140). 1930 (Fig. 7)

Holótipo: Brasil, Pará: estrada nova do Pinheiro, aquém do Tapanã, 17/11/1923, A. Ducke s/n, RB20390 (fl), 27/05/ 1926 (fr), 17/07/1926 (fol), (F, K, M, MO, RB, RE, S, SP).

Árvore de grande porte, $30-48 \mathrm{~m}$ alt., $30-110 \mathrm{~cm}$ DAP; tronco reto, cônico; base com sapopemas bem desenvolvidas, de 1,0- 


\section{ACTA \\ AMAZONICA}

CONTRIBUICCÃO AO CONHECIMENTO MORFOLÓGICO DAS ESPÉCIES

DE LEGUMINOSAE COMERCIALIZADAS NO ESTADO DO PARÁ, COMO "ANGELIM"
2,5 m do solo; ritidoma marrom-avermelhado, com estrias rasas, reticulado, com depressões formando manchas claras, estrias superficiais paralelas em linhas verticais, formadas por pequenas lenticelas; casca morta marrom-avermelhada, clara, fina ( $<1 \mathrm{~mm}$ espessura); casca viva amarelo-alaranjada a rosada, com até $5 \mathrm{~mm}$ espessura; exsuda resina incolor, escassa, com odor que lembra pepino; alburno amarelo-alaranjado, claro com fibras escuras. Folha imparipinada, 8,0-11,0 cm compr.; pecíolo canescente-tomentoso, 3,3-7,0 cm compr., estriado, cilíndrico; raque foliar cilíndrica, tomentosa, estreitamente canaliculada na parte superior. Folíolos 5-9, com 1,8-6,4 cm compr., 1,3-2,9 cm larg., alternos, obovados e oblongos, coriáceos; base obtusa ou levemente cuneada, ápice retuso, margem revoluta; face superior glabra, opaca, provida de papilas; face inferior moderadamente pubescente/canescente; peciólulos 2-4 mm compr. Inflorescência em heterocládio

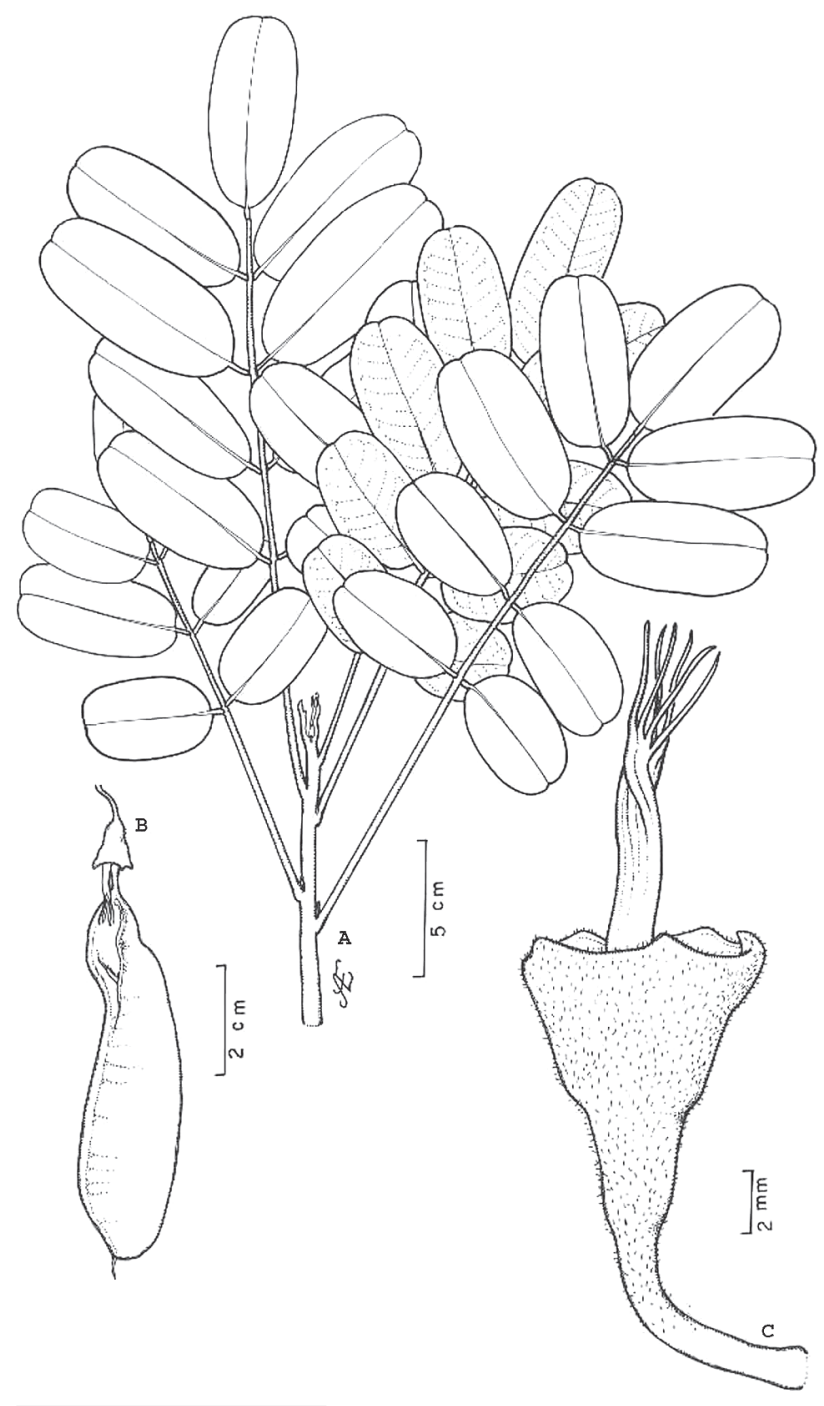

Figura 7 - Vatairea paraensis Ducke - A) ramo estéril ; B) fruto; C) cálice e androceu. A de N.T. da Silva 3004 (IAN); B \& C de N.T.da Silva 3065 (IAN). duplo racemo, terminal. Flor 20-25 mm compr.; pedicelo 6,08,0 mm compr.; cálice 8-27 mm compr., amarelo-ferrugíneo, tomentoso, quase preto; pétalas lilases a violáceas, de base esbranquiçada, $15-19 \mathrm{~mm}$ compr.; vexilo $15-17 \mathrm{~mm}$ compr.; alas 14-18 mm compr.; peças da carena $15-18 \mathrm{~mm}$ compr.; estames 10, monadelfos, concrescidos, 15-19 mm compr.; antera dorsifixa $0,8 \mathrm{~mm}$ compr.; gineceu $20 \mathrm{~mm}$ compr.; ovário súpero, tomentoso, subfalcado, curto-estipitado, unilocular. Fruto sâmara, oval, 6,7-12,5 cm compr., 1,1-3,0 cm larg., pericarpo bem desenvolvido, fibroso, ala apical, apículo terminal persistente, expansões aliformes sobre o núcleo seminífero. Semente 1.

Áreas de ocorrência na Amazônia brasileira (Fig. 8): Amazonas: Reserva Florestal Ducke. Pará: Belém, estrada do Munguba, Km 14, Moju (Campo Experimental da Embrapa), Paragominas, região do Jari, estrada entre São Miguel e Braço, Tailândia, Ulianópolis. Ocorre principalmente em florestas de terra firme do Estado do Pará, sendo registrado sua ocorrência no estado do Amazonas.

Nomes vernaculares: Amargoso (AM, AP, PA), angelimamargoso (PA), fava-amarela (PA), fava-amargosa (AM, PA), faveira (AM, AP, PA), faveira-amarela (PA), faveira-amargosa (PA), faveira-bolacha (PA), faveira-sapupira-amarela (AC, AM, PA), sapupira-amarela (RO) (Camargos et al. 2001; Lima 1982b).

Material examinado: BRASIL: Amazonas: Manaus, Reserva Florestal Ducke, 20/03/1998, fl, M.R. Mesquita et al. 30 (INPA). Pará: estrada do Munguba, km 14, 23/04/ 1970, fr, N.T.da Silva 3065 (IAN); região do Jari, estrada entre São Miguel e Braço, 25/03/1970, fr, N.T.da Silva 3004 (IAN); ibdem, 20/05/1970, fl, idem 3142 (IAN).

Reconhecimento no campo: As marcas amareladas, digitadas evidentes no ritidoma avermelhado, estriado, as grandes sapopemas e principalmente a cor lustrosa da face superior e inferior esbranquiçada dos folíolos são as principais características de identificação no campo.

Segundo comunicação pessoal com motosseristas e mateiros das empresas visitadas, o pó de Vatairea paraensis expelido durante o corte/exploração, contém substância que irrita (coceira) os olhos, algumas vezes causando cegueira, apesar do uso de óculos.

De 21 espécies de Leguminosae identificadas, sendo conhecidas no estado do Pará como angelim e derivações, sete espécies foram coletadas sendo comercializadas com esta denominação vernacular. As principais características utilizadas para separar as espécies foram: folhas, folíolos e aspectos gerais da árvore (ritidoma, casca morta e casca viva), quando em período estéril, no campo. Para as espécies de Andira, Hymenolobium e Vatairea, quando em período fértil, há necessidade de dados de órgãos reprodutivos, visto que nesta fase apresentam-se geralmente, desprovidas de folhas.

$\mathrm{Na}$ análise microscópica de órgãos reprodutivos, a forma e tamanho do ovário são muito úteis para separar as espécies desses gêneros. Apesar dos estudos morfológicos e até mesmo de seqüenciamento $r c b \mathrm{~L}$ já realizados para esses gêneros, a separação ainda é muito confusa. 
A

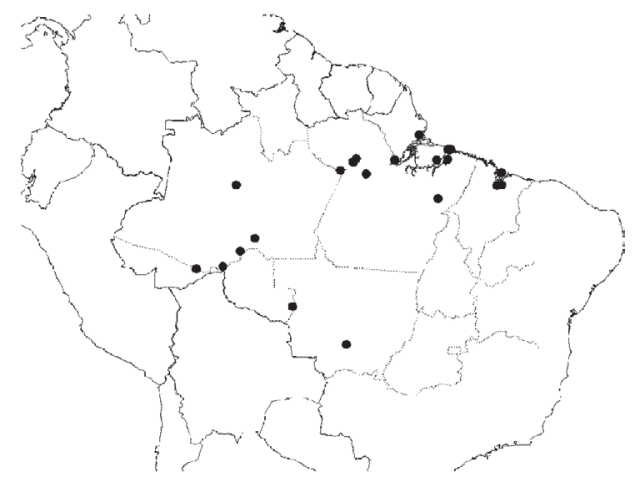

E

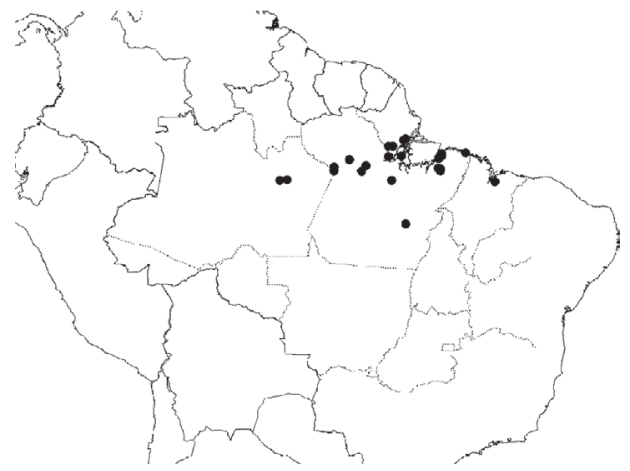

B

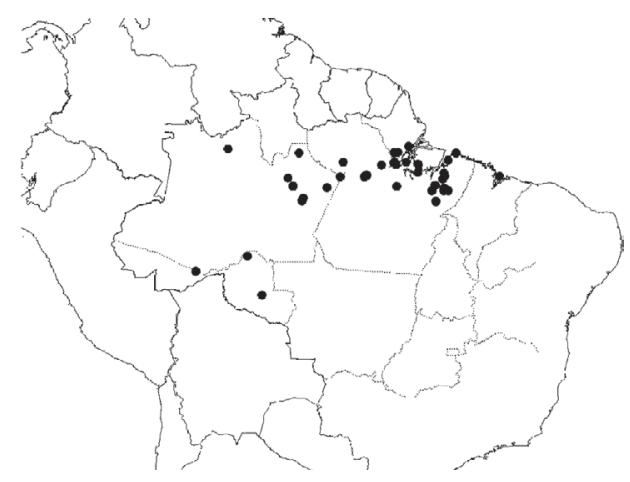

$\mathrm{F}$

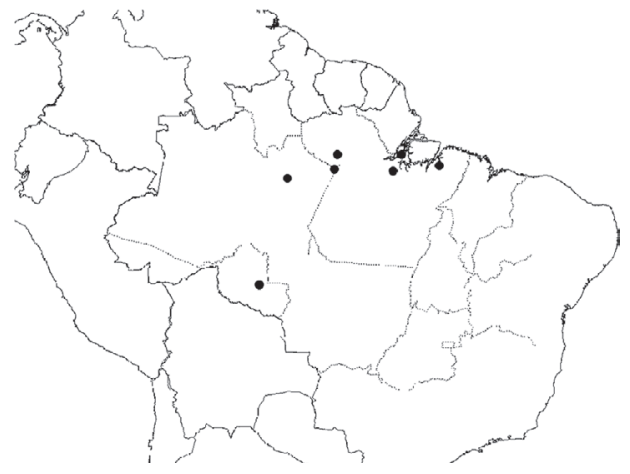

C

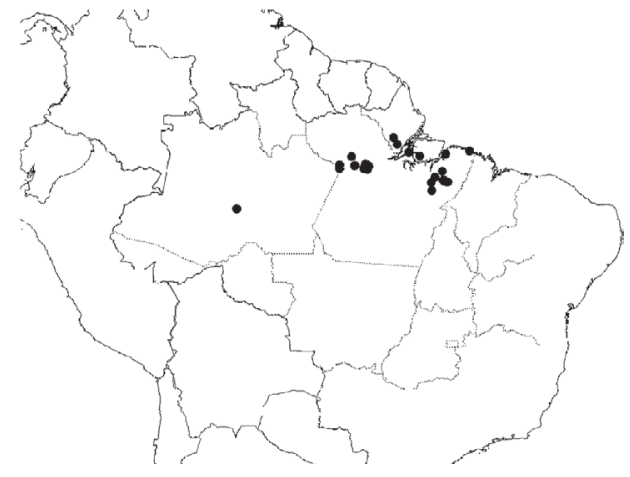

D

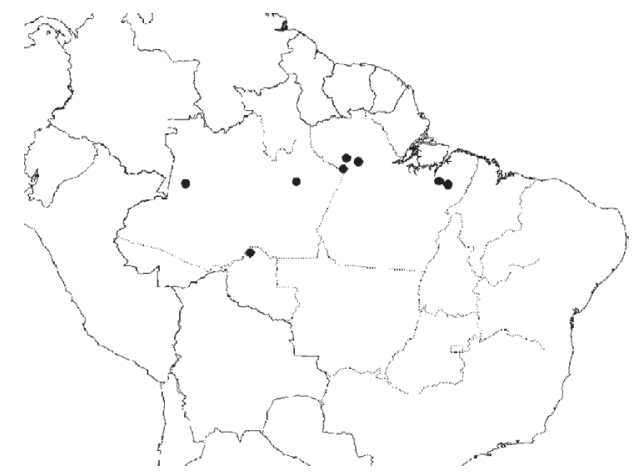

G

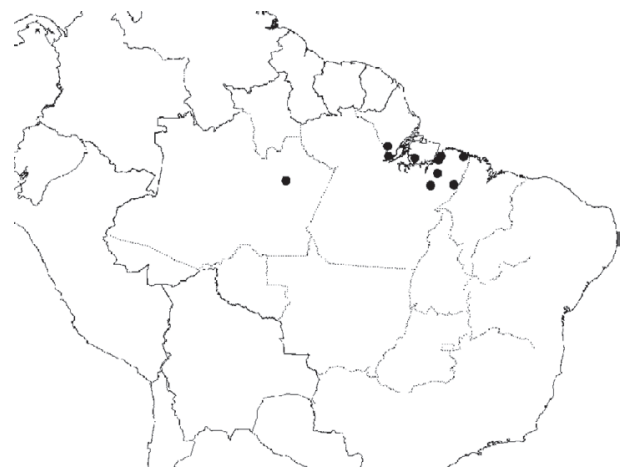

Figura 8 - Áreas de distribuição, na Amazônia brasileira, das sete espécies de Leguminosae comercializadas no Estado do Pará como angelim. A) Andira surinamensis; B) Dinizia excelsa; C) Hymenolobium excelsum; D) Hymenolobium modestum; E) Hymenolobium petraeum; F) Hymenolobium pulcherrimum; G) Vatairea paraensis. 


\section{ACTA \\ AMAZONICA}

CONTRIBUICÃO AO CONHECIMENTO MORFOLÓGICO DAS ESPÉCIES

DE LEGUMINNOSAE COMERCIALIZADAS NO ESTADO DO PARÁ, COMO "ANGELIM"
Características morfológicas de fruto também são muito úteis na separação das espécies sendo drupa em Andira, sâmara em Vatairea e Hymenolobium, com alas terminais e expansões aliformes sobre o núcleo seminífero em Vatairea, e com alas laterais e núcleo seminífero central em Hymenolobium, e legume samaróide em Dinizia.

Dinizia excelsa dificilmente é confundida com as demais espécies, pelo tipo de folha, bipinada, pelo desprendimento da casca em grandes placas coriáceas e irregulares, e inflorescência espiciforme.

\section{BIBLIOGRAFIA CITADA}

Barroso, G.M.; Peixoto, A.L.; Ichaso, C.L.F.; Costa, C.G.; Guimarães, E.F.; Lima, H.C.de. 1991. Sistemática de Angiospermas do Brasil, vol 2. Imprensa Universitária, Minas Gerais. 377p.

Barroso, G.M.; Andreata, R.H.B.; Lima, M.P.M.de. 1997. Morfologia de inflorescências. Univ. Santa Úrsula, Depto. Biologia Vegetal, Rio de Janeiro. 113p. (Apostila Revisada e Ampliada)

Barroso, G.M.; Morim, M.P.; Peixoto, A.L.; Ichaso, C.L.F. 1999. Frutos e sementes: morfologia aplicada à sistemática de dicotiledôneas. UFV, Viçosa. 443p.

Bentham, G. 1876. Leguminosae suborder Mimoseae Genera Plantarum, 2(1):536-598

Bukart, A. 1952. Las Leguminosas argentinas silvestres $y$ cultivadas. ACNE Agency, Buenos Aires. 560p.

Camargos, J.A.A.; Coradin, V.T.R.; Czarneski, C.M.; Oliveira, D. de.; Meguerditchian, I. 2001. Catálogo de árvores do Brasil. IBAMA-Laboratório de Produtos Florestais, Brasília. 896p.

Doyle, J.J.; Chappill, J.A.; Bailey, D.C.; Kajita, T. 2000. Towards a comprehensive phylogeny of legumes: evidence from $r b c \mathrm{~L}$ sequences and non-molecular data. Advances in Legume Systematics, 9: 1-20

Ducke, A. 1915. Leguminosae in Plantes nouvelles ou peu connues de la région Amazoniense. Arch. Jard. Bot. Rio de Janeiro, 1:12-42.

Ducke, A. 1922. Plantes nuvelles ou peu connues de la région Amazoniense. Arch. Jard. Bot. Rio de Janeiro, $3^{\mathrm{a}}$ parte, $158 \mathrm{p}$.

Ducke, A. 1949. Notas sobre a flora neotrópica II. Bol. Tec. Inst. Agron. Norte, n.18, 248p.

Ferreira, G.C.; Martins-Da-Silva, R.C.V.; Hopkins, M.J.G. (no prelo). Uso de nomes comuns na comercialização de madeiras no Estado do Pará - O exemplo do angelim. Brasil Florestal.

Instituto de Botânica (São Paulo). 1984. Técnicas de Coleta, Preservação e Herborização de Material Botânico. 61p. (Manual No 4)

Joly, A.B. 1993. Botânica; introdução à taxonomia vegetal. Ed. Nacional, São Paulo. 777p.

Judd, W.S.; Campbell, C.S.; Kellogg, E.A.; Stevens P.F. 1999. Plant Systematics: A phylogenetic approach. Sinauer Associates, Sunderland, USA, 464p.

Le Cointe, P. 1934. A Amazônia brasileira III - Árvores e Plantas Úteis (indígenas e aclimadas). Livraria Clássica, Belém. 486p.

Lewis, G.P.; Owen, P.E. 1989. Legumes of the Ilba de Maracá. Royal Botanic Gardens, England. 88p.

Lima, H.C.de. 1980. Revisão taxonômica do gênero Vataireopsis Ducke (Leg.Fab.). Rodriguésia, 32(54): 21-40
Lima, H.C.de. 1982a. Considerações taxonômicas sobre o gênero Hymenolobium Bentham (Leguminosae-Faboideae). Acta Amazonica, 12(1): 41-48

Lima, H.C.de. 1982b. Revisão taxonômica do gênero Vatairea Aublet (Leguminosae-Faboideae). Arq. Jard. Bot. Rio de Janeiro, 26: 173-213

Lima, H. C. de; Correia, C.M.B.; Farias, D. S. 1994. Leguminosae. In: M.P.M. de Lima; R.R. Guedes-Bruni (eds). Reserva Ecológica de Macaé de Cima: Nova Friburgo-RJ: Aspectos Florísticos das Espécies Vasculares. Jard. Bot. do Rio de Janeiro, Rio de Janeiro. p.167-228

Loureiro, A.A.; Freitas, J.A.de; Freitas, C.A.A.de. 1997. Essências Madeireiras da Amazônia vol.3. MCT/INPA-CPPF, Manaus. 103p.

Luckow, M.; White, P.J.; Bruneau, A. 2000. Relationships among the basal genera of Mimosoid legumes. Advances in Legume Systematics, 9:165-180

Mainieri, C.; Primo, B.L. 1968. Madeiras denominadas "angelim", estudo anatômico macro e microscópico. Anu. Bras. Econ. Flor, 19: 39-87

Mattos, N.F. 1979a. O gênero Andira Lam. no Brasil. Acta Amazonica 9(2): 241-266

Mattos, N.F. 1979b. O Gênero Hymenolobium Benth. no Brasil. Roessleria 3(1): 13-53

Mekdece, F.S.; Figueira, A.M.; Lobato, T.A. 1999. Métodos para superação de dormência de sementes de Dinizia excelsa Ducke (angelim pedra). SUDAM, Belém. 16p.

Muniz G.I.B.de. 1986. Descrição da estrutura e ultraestrutura da madeira de cinco espécies de Prosopis da Argentina e análise as metodologia. Dissertação de Mestrado Curitiba, Universidade Federal do Paraná, Curitiba, Paraná. 192p.

Pennington, R.T. 2003. Monograph of Andira (LeguminosaePapilionoideae). Systematic Botany Monographs, 64:1-143.

Polhill, R.M. 1981. Dalbergieae. In: R.M. Polhill; P.H. Raven (eds). Advances in Legume Systematics Part 1. Royal Botanic Gardens, England. p.233-242.

Polhill, R.M.; Raven, P. H. 1981. Advances in Legume Systematics Part 1. Royal Botanic Gardens, England: 425p.

Ribeiro, J.E.L. da S.; Hopkins, M.J.G.; Vicentini, A.; Sothers, C.A.; Costa, M.A. da S.; Brito, J.M. de; Souza, M.A.D. de; Martins, L.H.P.; Lohmann, L.G.; Assunção, P.A.C.L.; Pereira, E. da C.; Silva, C.F. da; Mesquita, M.R.; Procópio, L.C. 1999. Flora da Reserva Ducke: Guia de identificação das plantas vasculares de uma floresta de terra-firme na Amazônia Central. INPA, Manaus. 816p.

Rodrigues, R.M. 1989. A flora da Amazônia. $2^{\text {a }}$.ed. Cultural CEJUP, Belém. 462p.

Salazar, E.V. 1993. Papilionoideae Lindley. In: T.J. Killeen; E.G Estigarribia; S.G. Beck (eds.) Guía de Arboles de Bolivia. Herbário Nacional de Bolivia/Missouri Botanical Garden, Bolívia. p.457-485.

Stearn, W.T. 1983. Botanical Latin. David \& Charles, London. 565p. 